Running Head: UNVEILING AN EXCLUSIVE LINK

\title{
Unveiling an Exclusive Link: Predicting Behavior with Personality, Situation Perception, and Affect in a Pre-Registered Experience Sampling Study
}

\author{
Kai T. Horstmann ${ }^{1}$, John F. Rauthmann², Ryne A. Sherman ${ }^{3}$, Matthias Ziegler ${ }^{1}$ \\ ${ }^{1}$ Humboldt-Universität zu Berlin (Germany) \\ ${ }^{2}$ Universität Bielefeld (Germany) \\ ${ }^{3}$ Hogan Assessment Systems, Tulsa (USA)
}

This paper has been accepted for publication at Journal of Personality and Social Psychology (April 27, 2020). This version has not been copy-edited.

Please cite this version as:

Horstmann, K. T., Rauthmann, J. F., Sherman, R. A., \& Ziegler, M. (accepted). Unveiling an Exclusive Link: Predicting Behavior with Personality, Situation Perception, and Affect in a Pre-Registered Experience Sampling Study. Journal of Personality and Social Psychology.

\section{Author Note}

All materials, analysis scripts, data sets, as well as additional results can be found on the Open Science Framework: https://osf.io/zctv4/. For Study 1, we used existing data Sherman and colleagues (2015). The current study does therefore not provide the original materials for the replication of Study 1 (although Study 2 is a replication of Study 1).

The Pre-Registration for Study can be found on the Open Science Framework: https://osf.io/bzv5q/.

Correspondence: Kai T. Horstmann, Department of Psychology, Humboldt-Universität zu Berlin, Rudower Chaussee 1, 12489 Berlin, Germany. Email: kaitobiashorstmann@gmail.com. 


\begin{abstract}
Affect and situation perception are intertwined in any given situation, but the extent to which both predict behavior jointly and uniquely has not yet been systematically examined so far. Using two studies with experience sampling methodology (ESM), we examine how trait-like variables (Big Six, trait affect, general situation experience) and state-like variables (momentary affect, happiness, and situation perception) account for variance in self-reported behavioral states of the Big Six. In Study 1, we re-analyzed data from Sherman, Rauthmann, Brown, Serfass, and Jones (2015) and found that situation perception explained variance in self-reported behavior in logically coherent ways, but only after considering happiness as an additional predictor. These results were replicated in pre-registered Study 2, in which positive and negative affect were additionally assessed as distinct variables. Based on both studies, we conclude that personality traits, affect, and situation perception contribute uniquely to the explanation of self-reported behavior in daily life. Importantly, situation perceptions and affect do overlap, but they are neither the same nor redundant with each other. Indeed, theoretically justified and logically coherent links between situation perceptions and behavioral states remain intact once affect is controlled for, while the links not predicted by theory disappear. These results have implications for personality theories as well as appraisal theories of emotion.
\end{abstract}

Key words: situation perception, affect, behavior, DIAMONDS, experience sampling 


\section{Unveiling an Exclusive Link:}

\section{Predicting Behavior with Personality, Situation Perception, and Affect in a Pre-Registered Experience Sampling Study}

The idea that people differ consistently from others in their behavior, yet vary in their own behavior across situations and time, is hardly a new one. Kurt Lewin (1936) proposed that a person's momentary behavior B can be predicted by their current mental states $\mathrm{P}$ and the actual environment $\mathrm{E}$ they currently are in: $\mathrm{B}=f(\mathrm{P}, \mathrm{E})$. The person variables $\mathrm{P}$ have later been understood in terms of personality traits, and the environmental variables $\mathrm{E}$ as parts of the psychological situation (e.g., Funder, 2006). In an attempt to unravel how these variables functioned together, Sherman and colleagues (2015) examined in a large experience sampling (ESM) study how personality traits and psychological situation characteristics predicted momentary personality expressions (personality states) in daily life. They successfully demonstrated that both traits and situation characteristics independently accounted for variance in behavior. Furthermore, they expected that situation perception dimensions would be associated with some, but not all behaviors, hence showing a "discriminant association pattern" (Campbell \& Fiske, 1959; Siegling, Petrides, \& Martskvishvili, 2015; Ziegler \& Bäckström, 2016). A discriminant association pattern means here that situation perception dimensions are linked to other variables (e.g., self-reports of behavior) in logically coherent, plausible ways, instead of showing a positive manifold of undifferentiated associations. However, as we show in our current study, a discriminant association pattern could only be observed when affect, an important and theoretically relevant as well as potentially competing predictor of behavior in a situation (Lench, Flores, \& Bench, 2011), is integrated into the analyses. In the present article, we therefore examine the role of affect and its interplay with other, established predictors of 
behavior - personality and situations. We thus are able to not only replicate and corroborate, but also extend prior research on the interplay between persons and situations.

\section{Background}

\section{Explaining Behavior}

Before engaging in a discussion on how personality, affect, and situations together shape behavior, we first want to define those terms. Behavior, broadly defined, includes "actions, cognition, motivation, and emotions" (Fleeson \& Noftle, 2008, p. 1358). A more narrow definition focuses on actions by a person that are potentially available to careful observers using normal sensory processes (Furr, 2009, p. 372), which would exclude thoughts and feelings as long as these are not explicitly expressed. For the current article, we operationalize behavior as the self-reported account of current actions in a given situation, as often done in current experience sampling practices (Horstmann \& Ziegler, in press; Sherman et al., 2015; Wilson, Thompson, \& Vazire, 2017; Wilt \& Revelle, 2017). ${ }^{1}$ This definition is consistent with the term "personality states", being defined as "having the same affective, behavioral, and cognitive content as a corresponding trait (...), but as applying for a shorter duration" (Fleeson \& Jayawickreme, 2015, p. 84), or, as Baumert and colleagues (2017, p. 528) put it, "quantitative dimension[s] describing the degree/extent/level of coherent behaviours, thoughts, and feelings at a particular time." In this work, we focus on three broad categories of predictors of such momentary behavior: personality traits, situations and their perceptions, and affect.

Personality Traits. A trait, in its broadest definition, is a stable characteristic of a person (Funder, 2001), or, more specifically the level of coherent thoughts, behaviors, or feelings of a

\footnotetext{
${ }^{1}$ To keep with Sherman et al.'s (2015) terminology which is also used by others (e.g., Fleeson, 2004; Funder, 2006) as well as the pre-registration of the current study, we use the term "behavior" to concisely refer to self-reported explicit ratings of personality states.
} 
person (Baumert et al., 2017). Traits have been understood in taxonomic systems containing a varying number of factors. However, five to six broad factors describing basic tendencies, such as the Big Five (Funder, 2001; Pervin \& John, 1999) or the HEXACO model (Ashton \& Lee, 2007; Lee \& Ashton, 2008), are most prominent. The HEXACO model, which we will also use in the current study, contains the dimensions Honesty/Humility, Emotionality, eXtraversion, Agreeableness, Conscientiousness, and Openness. We chose the HEXACO model as it includes an additional important dimension compared to the Big Five model (Ashton \& Lee, 2001), and, more importantly, was also used by the authors of the original study that we replicate here (Sherman et al., 2015). Personality traits allow accounting for variance in behavior and predicting important outcomes (Ozer \& Benet-Martínez, 2006; Roberts, Kuncel, Shiner, Caspi, \& Goldberg, 2007; Soto, 2019). At the same time, traits-operationalized usually as a fixed value assigned to a person, therefore varying from person to person - are not well suited to explain variations in behavior from situation to situation: A person usually characterized as extraverted may behave introvertedly. This seemingly "inconsistent" behavior cannot be fully accounted for by the trait (Fleeson, 2004; Mischel \& Shoda, 1995; Sherman, Nave, \& Funder, 2010; Shoda \& Mischel, 2000). As Sherman and colleagues (2015) summarized, recent personality theories acknowledge that manifestations of personality, that is, personality states, can be different from the corresponding personality trait (Whole Trait Theory: Fleeson \& Jayawickreme, 2015; Five Factor Theory: McCrae \& Costa, 2008; Cognitive-Affective Processing Systems: Mischel \& Shoda, 1995; Trait Activation Theory: Tett \& Guterman, 2000). A personality state should be understood as situation-specific and can vary from situation to situation (Geiser et al., 2015; Horstmann \& Ziegler, in press; Steyer, Mayer, Geiser, \& Cole, 2015; Steyer, Schmitt, \& Eid, 1999). In most models this means that states are not just error, but actually 
contain variance that is systematic and therefore potentially explainable by (a) the corresponding personality trait (b) external situational influences and (c) other situation-specific characteristic of the person (e.g., ongoing affect). These points are important because explanations of states should not only be sought in characteristics of the person, of the external or current situation (Sherman et al., 2015), but also in internal specifics of the person in the situation (Cattell, 1963; Horstmann, Ziegler, \& Ziegler, 2018; Read, Smith, Droutman, \& Miller, 2017): A person that is characterized as introverted may act extraverted from time to time, either because the external situation factors afford it (such as being on a party) or momentary internal factors allow it (such as being in a very good mood or being drunk). We will therefore consider both potential predictors of behavior, situations and affect.

Situations. The situation (i.e., the momentary environment of a person) plays an important role in the explanation and prediction of momentary behavior (Deinzer et al., 1995; Fleeson, 2004; Furr \& Funder, 2004; Mischel \& Peake, 1982; Sherman et al., 2010, 2015; Shoda, Mischel, \& Wright, 1994). However, to examine the role of situations in the prediction of behavior more generally, it is necessary to first describe situations systematically and then to provide measures for situational information.

Situational taxonomies and measures. Rauthmann and colleagues (Rauthmann, 2015; Rauthmann et al., 2014; 2015) proposed that there are three kinds of situational information: cues (physical elements in an environment; e.g., a chair), characteristics (psychological meaning of cues; e.g., a situation may require that a task needs to be done), and classes (groups of situations similar in cues and/or characteristics; e.g., work-related situations). Rauthmann and colleagues (2015) argued that one of the most fruitful levels to study and understand situations is in terms of their psychologically meaningful characteristics. Situations can then be described and compared 
on a set of continuous dimensions (Horstmann, Rauthmann, \& Sherman, 2018; Rauthmann, Horstmann, \& Sherman, 2020). The question then is which dimensions should be used?

In the last 50 years, several situational taxonomies have been developed, and most taxonomies focused on the description of situation characteristics (Horstmann, Rauthmann, et al., 2018). However, only few and recently published taxonomies provided psychometrically validated assessment tools to measure such characteristics (i.e., Brown, Neel, \& Sherman, 2015; Gerpott, Balliet, Columbus, Molho, \& de Vries, 2017; Oreg, Edwards, \& Rauthmann, 2020; Parrigon, Woo, Tay, \& Wang, 2017; Rauthmann et al., 2014; Ziegler, Horstmann, \& Ziegler, 2019). The most widely used taxonomy so far is the DIAMONDS taxonomy (Rauthmann et al., 2014; Rauthmann \& Sherman, 2016a, 2016c). According to this taxonomy, situations can be described on eight dimensions. To assess these dimensions, participants are asked how they perceive a specific situation on: Duty (e.g., “work needs to be done”), Intellect (e.g., "deep thinking is required"), Adversity (e.g., "someone is being threatened"), Mating (e.g., "potential romantic partners can be attracted"), pOsitivity (e.g., "the situation is positive, playful"), Negativity (e.g., "the situation could be tainted by negative feelings"), Deception (e.g., "someone can be deceived"), and Sociality (e.g., "meaningful social interaction is possible or required"). These subjective situation judgments can then be used to explain in situ behavior (Rauthmann et al., 2014; Sherman et al., 2015).

Situation perception and behavior. Several studies have examined the powerful and robust effects that situations have on behavior. In fact, the manipulation of situation cues represents one of the central experimental designs of social psychology (Horstmann, Rauthmann, et al., 2018; Krueger, 2009). Further, situation characteristics have been shown to predict the expression of certain related behaviors (Fleeson, 2007; Judge, Simon, Hurst, \& Kelley, 2014), and this is also 
true for situation classes (e.g., Geukes, Nestler, Hutteman, Küfner, \& Back, 2017; Oud, Voelkle, \& Driver, 2017). However, as Sherman and colleagues (2015) point out, most of the situation measures used in these studies were defined ad hoc rather than systematically. With the advent of situational taxonomies and measures, effects of situations have been examined more systematically. Situation characteristics that were assessed with standardized and validated measures allowed theoretically meaningful predictions of behavior in several instances (Brown et al., 2015; Gerpott et al., 2017; Parrigon et al., 2017; Rauthmann et al., 2014; Ziegler et al., 2019). Further, several situation dimensions have been explicitly linked to behavioral manifestations of personality traits (de Vries, Tybur, Pollet, \& van Vugt, 2016; Parrigon et al., 2017; Rauthmann, Jones, \& Sherman, 2016; Sherman et al., 2015).

More specifically, the DIAMONDS dimensions were argued to have exclusive links to the HEXACO dimensions of personality and their manifestations (Rauthmann et al., 2016; Rauthmann \& Sherman, 2018a; Sherman et al., 2015). For example, perceiving Duty in a situation should predict conscientious behavior, but not honest behavior. Sherman and colleagues predicted and examined several specific combinations of situation characteristics and personality state behavior (see upper third of Table 1). The idea that situation perception dimensions are exclusively linked to some personality state behaviors but not others is similar to the idea of discriminant validity, as introduced by Campbell and Fiske (1959). In terms of a "discriminant association pattern," it is important here that the perception of a situation on a specific characteristic dimension is linked to a specific behavior in a logically coherent way. If this were not the case, and any situation characteristic dimension were linked to any behavior, at least two explanations would be possible. 
First, individual differences in response style (e.g., acquiescence, extreme responding, etc.), or socially desirable responding (i.e., a tendency to present oneself as positive), could drive undifferentiated associations. Variance attributable to such phenomena would affect personality and situation characteristics likewise and this common method variance would increase correlations between otherwise uncorrelated scores (Holden \& Passey, 2010; Ziegler \& Buehner, 2009). If this were the case, it would be questionable if situation characteristics and behavior can be validly assessed — especially with respect to discriminant associations — at all in real-life or if participants' responses follow an artificial positive-manifold pattern (similar to a commonmethod factor) which is unrelated to the (specifics of the) current situation.

\section{- Table $1-$}

Second, participants may evaluate real-life situations on a broader, more general level and do indeed not thoroughly discriminate nuances of situation characteristics (i.e., such indiscrimination is not just a product of a common method factor). Such "general" evaluations could be in line with appraisal theories of affect where the affect of a perceiver may be driving how the situation is perceived (Rauthmann \& Sherman, 2018b; Rauthmann et al., 2015). This would mean that a situation perception score of an individual person would primarily reflect their momentary general evaluation of the situation, and not a specific perception of a situational characteristic. Again, the result would be shared variance between situation characteristic scores. In turn, this would severely question the validity of in situ measures of situation perception. Similar to the examination of convergent and discriminant associations when establishing a construct's nomological net (Campbell \& Fiske, 1959; Cronbach \& Meehl, 1955), it is therefore important to first examine the specificity of the situation-behavior links proposed in Table 1, and then to gauge the role of other evaluative constructs, such as affect. 
Affect. Affect (or mood; Watson \& Gray, 2007) is a diffuse, evaluative but "consciously accessible" (Russell, 2003, p. 147) state that can be either positive or negative and activated or deactivated (Russell, 2003; Watson \& Tellegen, 1985; Winkielman, Knutson, Paulus, \& Trujillo, 2007; Yik, Russell, \& Barrett, 1999). As such it can be "felt [as a] tendency to approach or avoid" (Larsen, 2000, p. 130). Affect can be distinguished from emotion primarily because emotions are generally directed towards and tied to an object (e.g., Gendolla, 2000; Larsen, 2000), whereas affect can have many, unknown causes (Russell \& Barrett, 1999) and is more unspecific (Siemer, 2009). Further, emotions usually last seconds to minutes (but for a different perspective, see Verduyn, Delvaux, Van Coillie, Tuerlinckx, \& Van Mechelen, 2009), whereas affect lasts between hours and days (Watson \& Gray, 2007), but both are subject to intraindividual change (Kuppens, 2015).

Still, affect and emotion are closely tied to one another and often co-occur (Russell \& Barrett, 1999; Siemer, 2009). Both are also strong predictors of cognition and behavior (Gendolla, 2000; Lench et al., 2011). However, affect is especially suited as a predictor of behavior in situ. At the trait level, it has been shown that positive affect is correlated with extraversion (Fleeson, Malanos, \& Achille, 2002) and negative affect with neuroticism (Costa \& McCrae, 1980; Diener, Oishi, \& Lucas, 2003; Lucas \& Fujita, 2000). Correspondingly at the state level, acting neurotic or extraverted can lead to negative or positive affect, respectively (McNiel \& Fleeson, 2006). Positive and negative affect were further related to expressions of all Big Five personality traits in daily life (Wilson et al., 2017; Wilt, Bleidorn, \& Revelle, 2017; Wilt \& Revelle, 2017). ${ }^{2}$ We therefore examine affect as a predictor for behavior in daily life.

\footnotetext{
2 These studies support the claims and assumptions that we had when we first examined the data by Sherman and colleagues (2015). However, these studies were not published at the time and therefore did not inform the current research or any specific hypotheses in Study 1 or Study 2.
} 
Affect and situation perception. Affect is related to information processing (Forgas, 2000; Wyer, Clore, \& Isbell, 1999). For example, positive affect was found to be associated with less careful evaluation of information of persuasive communications (Bless, Bohner, Schwarz, \& Strack, 1990; Petty, Fabrigar, \& Wegener, 2003), participants with happier moods evaluated stimuli less profoundly than participants in a negative mood (Gasper \& Clore, 2002), and angry people tend to be more optimistic with regard to taking risks (Lerner \& Keltner, 2001). As such, affect may also exert an influence on the interpretation and evaluation of situational information (Horstmann \& Ziegler, 2019; Rauthmann, 2012, 2016; Rauthmann et al., 2015).

On the other hand, appraisal theories of emotions posit that persons evaluate their environment based on their current "concerns, goals, and competencies $[\ldots]$ and that the outcome of this appraisal process is associated with specific emotional experiences" (Kuppens, 2009, p. 255). The subjective perception of the individual's situation should thus elicit (rather than is elicited by) certain affective responses (Griner \& Smith, 2000; Kuppens, 2009; Kuppens \& Van Mechelen, 2007; Moors, 2014; e.g., Sander, Grandjean, \& Scherer, 2005; Scherer, 2001). As Horstmann and Ziegler (2019) concluded, the perception of a certain situation characteristic (e.g., Duty as a demand to work) and the current state of the perceiver (e.g., a missing competency to cope with this demand) could result in negative affect as a downstream consequence. Additionally, measures of affect and situation perception show some semantic overlap (i.e., "the situation is positive" vs. "I am in a positive mood"), which may be another reason for their empirical overlap as well.

Both strands of theory and research — either positing affect governing situation perception or situation perceptions governing affect- - together suggest that perceived situation characteristics and affect should in general be tied to one another. However, the exact causal 
relation and direction(s) remain problematic to examine thus far. It may stand to reason that situation perceptions and affect influence each other or are even inextricably intertwined. In the latter case, situation perceptions may have no incremental value above and beyond affect (and vice versa) as scores for both would be contaminated by each other or form an amalgamation. This would mean that once controlling for affect, situation perception might not be tied to behavior anymore. Regrettably, though, so far only few studies have empirically examined relations between situation perception and positive or negative affect or related constructs (i.e., Edwards \& Templeton, 2005; Gerpott et al., 2017; Horstmann \& Ziegler, 2019; Parrigon et al., 2017; Serfass \& Sherman, 2013; Sherman, Nave, \& Funder, 2012; Sherman et al., 2015). Horstmann and Ziegler (2019) examined the relations of self-reported affect and situation perception assessed with the Situation Five (Ziegler et al., 2019) and the DIAMONDS (Rauthmann \& Sherman, 2016a). All situation perception dimensions were substantially correlated with either positive or negative affect (or both), and situation measures explained substantial proportions of variance in positive and negative affect $\left(R^{2}=.63\right.$ for positive affect and $R^{2}=.66$ for negative affect). These results are very similar to the findings presented by Parrigon and colleagues (2017) and Gerpott and colleagues (2017). Finally, Sherman and colleagues (2015) showed in experience sampling data that certain situation characteristics explained variance in state happiness in daily life.

As Horstmann and Ziegler (2019) argued, such links between situation perceptions and affect could be problematic for two related reasons. First, a lack of discriminant validity of measures of situation characteristics and affect would mean both are virtually indistinguishable once measured and thus hinder a clear understanding of the nomological networks of situation perception dimensions. For example, effects that are attributed to situation perception-and thus 
the influence of the situation - might have to be attributed to the in situ affect of the person rating the situation. Second, and related to the first point, measures of situation perceptions may harbor no incremental validity above measures of affect. If they do not predict more or other variance in behavior, it is then unclear why we should use them.

Taken together, this state of affairs calls for a more thorough investigation of the relations between situation perceptions and affect in daily life, especially when both are used to concurrently explain variance in behavior in situ. Given the strong overlap of situation perception and affect as well as their individual ability to predict in situ behavior, we examine how both simultaneously predict behavior.

\section{The Current Studies}

In this work, we examine the interplay of situation perception, affect, and behavior in daily life across two independent studies. The first study, exploratory in nature, is a re-analysis of the data from Sherman et al. (2015). Sherman and colleagues used state happiness as an outcome variable which was predicted by situation perception and personality traits. We re-examined the data and employed state and trait happiness as a predictor of behavior vis-à-vis situation perception. The results of these analyses were used to pre-register an extended replication in Study 2. Whereas no specific hypotheses for the effects existed for Study 1, specific predictions were made for the combined effects of affect and situation perception on behavior in Study 2 . Note that in both studies, we only used measures of happiness and affect, situation perception, and behavior that had been previously used, examining the validity of their scores to predict everyday behavior. An overview of the study details and which elements were pre-registered can be found in Table 2. All materials, analysis scripts, data sets, as well as additional results can be found on the Open Science Framework (OSF, https://osf.io/zctv4/). 


\section{Study 1}

Study 1 is a re-analysis of the data provided by Sherman and colleagues (2015) and primarily exploratory in nature. As Study 1 has mainly informed the hypotheses tested in Study 2, we do not report the results from Study 1 in much detail here. A detailed description of the methods, procedure, analyses, and results from Study 1 can be found in the Online Supplemental Materials A (OSM A). ${ }^{3}$

Sherman and colleagues (2015) assessed the HEXACO personality traits and their state manifestation (i.e., self-reported levels of momentary honesty/humility, emotional stability, extraversion, agreeableness, conscientiousness, and openness), subjective happiness at trait and state level, and the Situation Eight DIAMONDS (i.e., perceived momentary Duty, Intellect, Adversity, Mating, pOsitivity, Negativity, Deception, and Sociality) in daily life. Participants first completed various trait measures, which was followed by an experience sampling phase, in which participants reported various state measures. The authors reported logically coherent predictions of daily behavior and state happiness with personality traits and situation perception (see upper third of Table 1 for tested hypotheses by Sherman at al., 2015). The authors only tested those predictions in their analyses. For example, they tested whether perceiving a momentary situation as having high levels on Duty is related to higher momentary Conscientiousness. However, as a result, the degree to which other relations may exist among personality traits, situation characteristics, and daily experiences was not tested. The authors concluded that " $[\mathrm{u}]$ ltimately, both personality traits and experienced situation characteristics

\footnotetext{
${ }^{3}$ The data from Study 1 were initially published in Sherman et al. (2015). Since then, they were also used in Rauthmann et al. (2016), Jones et al., (2017), and Rauthmann et al. (2019). None of these articles has addressed the same questions that are addressed in the current study.
} 
appear to independently predict behavior" (Sherman et al., 2015, p. 886). We re-analyzed the data to examine (a) the discriminant association pattern of situation perception dimensions with behavior and (b) the role state affect/happiness played in the relations between traits, states, and situation perceptions.

\section{Research Question and Results}

On a very broad level, we were interested in the two research questions outlined above: First, are the proposed links between situation perception and behavior exclusive? For example, is it so that perceiving Intellect in a situation is only related to higher Openness, but not to higher levels of Conscientiousness? Second, given the previously reported overlap between affect and situation perception, does situation perception explain variance in behavior after including happiness as a simultaneous predictor?

To examine the first question, we fully crossed all assessed self-reported behaviors with all assessed situation characteristics: Using multi-level modeling, we predicted, for example, state conscientious behavior by perceived Duty. In a separate model, we then examined to what extent state conscientiousness could also be predicted by perceived Intellect (see Model 1 in Table 3), then, by perceived Adversity, and so on. Here, our re-analysis showed that at the situation level, each behavior assessed was indeed related to nearly each situation perception dimension. The links between behavior and situation perception were unspecific, that is, state conscientiousness was predicted by Duty, Intellect, or any other of the DIAMONDS dimensions - the effect of momentary situation perception on momentary behavior was statistically significant in all cases. In other words, scores of situation perception dimensions did not show a discriminant association pattern. 
For the second question, we extended the previous models and included state and trait happiness as additional predictors (see Model 2 in Table 3): For example, we predicted conscientious behavior by situation perception and the two happiness scores. Here, our reanalyses showed that situation perception at level 1 still predicted behavior at level 1, but mainly in those cases that were theoretically plausible (see Table A5 in OSM A). For example, while extraversion behavior could be predicted by perceived in situ Duty $(b=-0.05,95 \%$ CI [-0.07; $0.02])^{4}$, this effect was no longer statistically significant after controlling for state and trait happiness $(b=.0095 \% \mathrm{CI}[-0.02 ; 0.02])$. Hence, after controlling for happiness at the trait and state level, situation perception dimensions showed a discriminant association pattern, as expected.

- Table $3-$

\section{Discussion}

The re-analyses of Sherman and colleagues' (2015) data revealed two important insights. First, happiness, both as a trait and as a state, was a predictor of variance in everyday behavior: Happiness at state level predicted moment-to-moment variations in behavior, and happiness at trait level predicted person-to-person variations in behavior. This is in line with other recently reported findings (Wilson et al., 2017; Wilt \& Revelle, 2017). The re-analyses further revealed that state happiness and momentary situation perception overlapped (see also Horstmann \& Ziegler, 2019). Horstmann and Ziegler suggested that this overlap could be problematic for situation research: Effects attributed to situation perception might better be attributed to affect (or vice versa). However, as the results of our second analysis revealed, situation to situation variations in situation perception remained a statistically significant predictor of everyday

\footnotetext{
${ }^{4}$ As these are unstandardized estimates, a decrease in one unit on the predictor means that the criterion changes $b$ units on a scale from (in the case of extraversion) $1=$ "outgoing, sociable" to $8=$ "reserved, quiet".
} 
situation to situation variations in behavior even after controlling for state and trait happiness. For example, a person that is happy in a situation acts more extraverted in this situation, but persons that perceive the situation as social are likely to act even more extraverted (regression weight of in situ perceived Sociality on extraverted behavior: $b=0.21,95 \% \mathrm{CI}=[0.18,0.24], t=$ 13.65, see Table A6 in OSM A). Taken together, the theoretical model that assumes specific effects of situation perception on certain behaviors might in fact be more accurate when including state and trait happiness as an additional predictor.

If these findings were to be found replicable, they would support the validity of situation perception scores: Participants' in situ perceptions of situation characteristics could then be distinguished from their current affect with the measurement instruments we used. Moreover, each of the constructs uniquely contributed to the prediction of behavior in a theoretically sensible way. The perception of a situation would thus be more than just current affect/internal person states, and this additional variance in situation perception was systematic and tied to the behavior of the person in that situation. We will engage in broader discussion of these findings after presenting the results from Study 2 which extends the exploratory re-analyses of Study 1.

\section{Study 2}

There are some shortcomings of the re-analyses presented in Study 1, limiting the robustness of our initial findings and making a second study necessary, which we report here. First, the analyses reported in Study 1 were strictly exploratory. We did not have specific hypotheses other than the general research question of happiness and situation perception as combined predictors of behavior. We also did not expect to find the particular discriminant association pattern of exclusive effects of situation perception on behavior after controlling for happiness. Furthermore, we also tested different models (e.g., quadratic terms or cross-level- 
interactions); however, the results of these analyses could not be interpreted coherently and were therefore abandoned and not followed up on in Study 2. Performing many exploratory analyses results in an inflation of Type-I errors (Ioannidis, 2005; Simmons, Nelson, \& Simonsohn, 2011), which may result in detecting and placing value in potentially unreliable findings that ultimately cannot be replicated (see Open Science Collaboration, 2015). Thus, we needed to replicate our pattern of results.

Second, the measure of state happiness, created ad hoc for the assessment of happiness during experience sampling, was suboptimal as only one item with a bipolar rating scale was used. Although this procedure is common in emotion assessment and especially in experience sampling studies (Horstmann \& Ziegler, in press), it poses a threat for the validity and interpretation of the resulting affect score (Weidman, Steckler, \& Tracy, 2017). Further, affect has at least two dimensions, positive and negative, and could also be activating or deactivating (Russell, 2003; Watson \& Tellegen, 1985; Winkielman et al., 2007; Yik et al., 1999). These dimensions may be correlated, but they are nevertheless distinct (Dejonckheere et al., 2018). This distinction and heterogeneity were lost when using only one item for the assessment of affect. Based on the findings reported above, it could therefore be possible that a better, more differentiated, and more reliable measure of affect would "swallow" the remaining effects of situation perception on behavior. If this were the case, then the re-analyses in Study 1 would have painted an overly optimistic picture of the exclusive links between certain situation characteristic and certain behaviors (Table 1). Thus, a second study needed to employ a more differentiated measure of affect.

Due to these two limitations, we aimed to replicate and extend the study by Sherman and colleagues (2015) as well as our re-analysis reported in Study 1 in an independent sample with a 
better suiting affect measure. We pre-registered this replication on the Open Science Framework (OSF) in November 2016 and collected the data in 2016 and early 2017.

\section{Research Questions}

All hypotheses for the current study were pre-registered on November $21^{\text {st }} 2016$ on the OSF: https://osf.io/bzv5q/?view_only=9fc48b0011df411bb9ddc2726c50d34f. Instead of listing every hypothesis here, we will indicate in the results section if an effect turned out as expected. We deem a replication successful (a) if an effect that was previously shown to be statistically significant in Study 1 is also significant in the analyses of the new data in Study 2 (see Tackett et al., 2017, p. 743) and (b) if an effect that was previously not significant is also not significant in the replication.

We pre-registered that an effect would be considered statistically significant if its corresponding $p$-value is smaller than .05 . We further pre-registered to test all directed effects (i.e., positive or negative) in a one-tailed fashion, and all other effects in a two-tailed one. However, we will deviate from this pre-registration such that we test effects that were preregistered not to be significant now with an alpha level of .10, thereby accepting a larger Type-I error rate but also lowering the acceptance of the Type II error rate. The test of the hypotheses that an effect is not present is therefore stronger. This means that pre-registered positive or negative effects will be considered significant if the $90 \%$ confidence interval (one-tailed) excludes zero and the corresponding $t$-value is larger than $t=1.64$ (Wald $z$-test). Similarly, hypotheses that an effect is zero will be retained if the $90 \%$ confidence interval (two-tailed) includes zero and if the $t$-value of that effect is smaller than $t=1.64$. Effects that were not preregistered or hypothesized to be in any particular direction will be evaluated on an alpha level of .05 , two-tailed (e.g., effects of affect in the extended replication of Study 1). This approach is in 
line with current recommendations to justify the alpha level (Lakens et al., 2018) instead of applying a one-size-fits-all approach in form of one general level of significance (Benjamin et al., 2018).

\section{Overview}

Study 2 served several purposes. First, we aimed to replicate and extend Sherman and colleagues (2015) original findings. As this replication is not the primary purpose of the current study, the results of the replication can be found in the OSM B. OSM B contains all results that replicate Sherman and colleagues original work. Although a few effects during the replication did not turn out exactly as pre-registered, the overall replication can be deemed successful.

Second, we replicated the results from our re-analysis of Sherman and colleagues' data. Here, we considered three different models (see Table 3). First, we aimed to replicate our finding that effects of situation perception on behavior are unspecific, that is, each situation perception dimension predicts each behavior (Model 1), thereby showing a lack of discriminant association patterns. Second, we aimed to replicate that, when including happiness as an additional predictor, mainly the theoretically plausible, exclusive links between situation perception and behavior remain significant (Model 2). These first two analyses can be considered direct replications of our results presented briefly in Study 1. Finally, for reasons outlined above, we included better measures of state and trait affect that capture a wider range of the construct (Model 3).

\section{Method}

Pre-registration. In addition to the hypotheses, we explicitly pre-registered all variables collected, the planned number of participants (see below), and the data-analytical plan. For the data analyses, we pre-registered (1) how each variable would be collected, (2) how each scale would be scored, and (3) how each variable would be transformed prior to analyses in a 
multilevel-model. All items assessed as well as the transformation for each item can be found in the OSF C. We will explicitly mention which elements in the data analyses (see below) and data processing (see below) were pre-registered and where we deviated from the pre-registration.

Power analysis and determination of sample size. Based on Study 1, an a priori MonteCarlo simulation power analysis was performed to determine the needed sample size. The power to detect an effect in a multi-level model depends on the number of level 1 units (i.e., number of measurement occasions obtained), the number of level 2 units (i.e., participants sampled), as well as the size of the effect (Mathieu, Aguinis, Culpepper, \& Chen, 2012). As many different models had to be analyzed, we took the smallest effect of interest in the final model of Study 1 (i.e., when happiness was included both at the trait and state level in the model predicting agreeable behavior with Sociality) and examined the sample size necessary to replicate this effect with $80 \%$ power. For a one-tailed $t$-test (Wald, 1943) at alpha $=.05,60$ measurement occasions sampled across 250 participant yielded only $66 \%$ power. If the number of measurement occasions increased to $80,76 \%$ power would be obtained; 120 measurement occasions yielded a power $>80 \%$. On the other hand, larger effects (e.g., predicting Conscientiousness with Duty) yielded a power $>99.99 \%$. Based on these analyses, we decided to sample $N=250$ participants, aiming for $n=45$ measurement occasions per person. This will allow detecting small effects of interest (e.g., $b \mathrm{~s} \sim .10$ ) with sufficient power. At the same time, we used mainly one-tailed tests in Study 2, which further increases test power.

Sample and procedure. The data were collected using the open-source platform formr.org (Arslan \& Tata, 2015). Data collection took part in Germany. Participants were first informed about the study and required to submit their e-mail address to participate. Subsequently, participants received an e-mail with an invitation to respond to demographic questions and 
complete personality measures (see Trait Measures). After completing the initial assessment, participants received an e-mail every three hours with an invitation to respond to state measures (see below). The measures were presented in the same order each time. After each assessment, participants could opt out by unchecking a box. Either after opting out or after completing 50 measurement occasions, participants were directed to a website with a debriefing and a general invitation to participate in further studies. Participants then received personalized feedback via email on their personality trait levels, and their trajectories in situation perception, affect, and behavior over the course of their participation. If eligible, participants could also receive course credit for their participation.

In total, $N=1,128$ participants clicked on the link to the study, 367 submitted their e-mail, and 341 participants completed the initial personality assessment. Of these, 274 provided sufficient data in the experience sampling phase of the study to be included in further analyses. Participants were on average 24.22 years old $(S D=6.35) ; 14.96 \%$ percent were male, $84.31 \%$ were female, and $0.73 \%$ did not indicate their gender. Most participants were enrolled in a university program (90.51\%). The completion of the initial trait assessment took about 19 minutes to complete (maximum number of 80 items), and each experience sampling assessment on average about three minutes to complete. All materials required to replicate the study as well as a detailed procedure can be found on the OSF.

\section{- Table $4-$}

Ethics Statement. The current study was conducted in line with common ethical standards for the treatment of human participants at Humboldt-Universität zu Berlin, Germany. Specifically, participants were informed about the purpose of the study and how their data would be analyzed and shared in an anonymized format during the publication process. All participants 
could withdraw at any time from the study without any negative consequences. Participants could only participate after providing their informed consent.

Trait measures. For our replication to be very close to Study 1, we used the same measures that were used in Study 1 in their German version.

Personality Traits. The German version of the HEXACO-60 was used (Moshagen, Hilbig, \& Zettler, 2014). The six HEXACO personality dimensions were assessed with 10 items each. Items were answered on a 6-point rating scale $(1=$ "not accurate at all", $6=$ "completely accurate"). Descriptive statistics, sample items, and internal consistencies can be found in Table 4.

Subjective happiness. We used the German version of the subjective happiness scale (Lyubomirsky \& Lepper, 1999; Swami et al., 2009). It assesses subjective happiness with four items. Instead of using a 7-point rating scale, we changed this to an 8-point rating scale in order to avoid a middle category (Kulas \& Stachowski, 2009). Descriptive statistics, a sample item, and internal consistency are reported in Table 4.

State measures. We used the same measures as Sherman and colleagues for the assessment during experience sampling. Sample items, descriptive statistics, and reliabilities (if applicable) for all state measures are presented in Table 4. State measures were presented on three different pages. Participants first rated their current affect, then the current situation, and then their behavior in the situation.

Situation perceptions. For the assessment of situation perception, we used the Situation Eight DIAMONDS ultra-brief measure in its original German version (Rauthmann \& Sherman, 2016c). Participants responded on an 8-point rating scale how well each item describes the given, current situation. 
Behavior. Similar to Sherman and colleagues (2015), we used a bipolar rating scale for the assessment of current, in situ behavior. In total, seven different behaviors were assessed with one item each. Each item consisted of an 8-point rating scale, with two adjectives marking each endpoint. The items were translated from Sherman and colleagues' (2015) original study by a bilingual native speaker.

Happiness. Happiness was assessed with the same item as in Sherman et al. (2015). Participants rated their current happiness on a bipolar rating 8-point rating scale with the endpoints $1=$ "happy, positive" and $8=$ "sad, negative". This item was translated by a bilingual native speaker.

Affect. To assess momentary affect, we used adjective scales developed by Hampel (1977). Hampel originally developed six scales to assess six different aspects of affect or emotion. However, as we aimed to reduce participant burden and keep the number of items minimal during ESM assessment, we decided to assess only two scales, positive affect (PA, German gehobene Stimmung, e.g., cheerful, happy, elated) and negative affect (NA, German Missstimmung, e.g., angry, edgy, bad-tempered), which are closest to positive and negative affect. Hampel originally developed two parallel seven-adjective scales for each dimension. From the PA scale, we selected the three items with the highest factor loading presented in the original study by Hampel, 1977. From the NA scale, we selected three items that were still widely in use (e.g., brummig [grumpy], was not selected), or items that we deemed not to be too extreme for an application on everyday context (e.g., zornig [furious]). We decided to use a narrower instead of a broader operationalization of affect in order to obtain more reliable measures and potentially unidimensional scores, allowing better interpretation of the resulting effects. To further reduce participant burden, the activating - deactivating components of affect 
were also ignored. At each assessment, participants were instructed to rate how they feel during the current situation on an 8-point rating scale ( $1=$ "not accurate at all", $8=$ "completely accurate"). The scores for PA and NA were formed by taking the average of the three items at each assessment. Descriptive statistics are presented in Table 4. As noted earlier, the items that were used to assess affect and situation perception have some semantic overlap; however, it is at the core of the current investigation if this semantic overlap threatens the predictive validity and utility of situation perception measures.

Closeness of the replication. The current study is a replication and extension of the original study by Sherman and colleagues (2015) upon which our Study 1 here was based. However, Study 2 also differs in several aspects from Study 1. The main difference is of course the language and the country the study was conducted in. Whereas the first data collection took place in the US, the second data collection took place in Germany. However, both studies used mainly undergraduate (psychology) students. Further, the participant recruiting strategy, data collection, and remuneration differed between the two studies. In Study 1, participants were invited into the laboratory for the first session (assessment of personality measures), whereas in Study 2 all assessments took place online. Participants in Study 1 received course credit, and participants in Study 2 received feedback on their measures as well as course credit. Further differences between the studies concern the number of points used on the rating scales as well as the determination of the sample size. All differences between the two studies are listed in Table 5. All other elements (e.g., scales used, scoring of scale composites, software used) were kept identical, with the exception that all measures and instructions were in German.

To assess the outcome of the replication, it is important that both studies differ as little as possible, or only in aspects irrelevant to the effect examined. However, it is not easy to 
determine which aspects are relevant to the outcome of the study and which aspects are not. It was therefore our aim to replicate Study 1 as closely as possible. Based on the study differences presented in Table 5 we argue that Study 2 is a very close, direct replication of Study 1 (LeBel, Berger, Campbell, \& Loving, 2017). Different outcomes of the two studies should therefore not be attributed to the design, but to the robustness of the effects examined.

- Table 5 -

Processing of experience sampling data. We first excluded participants with less than four measurement occasions. We then excluded measurement occasions in which participants responded in less than 10 seconds (less than $1 \%$ of the measurement occasions). Finally, we checked the amount of missing data during experience sampling, and no variable had more than $1.20 \%$ missing data. Therefore, no data were imputed. This procedure was pre-registered. However, contrary to our pre-registration, we did not exclude participants that showed very long ( $>20$ minutes) reaction times as this would have meant to exclude 440 measurement occasions. These reaction times occurred when a participant clicked on a link but finished the survey later. Overall, we included an average of 30.2 measurement occasions per participant (see Figure 1 for a detailed overview and breakdown of the number of state assessments per person).

- Figure 1 -

Computation of scale scores and centering. We took the average of all items belonging to one scale to form the scale composite (e.g., all items for extraversion were averaged). The same procedure was applied for state positive and negative affect, as both were assessed with three items each. Finally, level 2 variables (at the person level) were grand-mean centered and level 1 predictors (at the situation level) were person-mean centered (Enders \& Tofighi, 2007). The means of level 1 variables (e.g., the mean of all items for Duty) were included in the multi- 
level models as level 2 predictors to account for between person mean differences. The computation of scale scores and the procedure of multi-level models analyzed exactly mirrors those in Study 1.

\section{Analyses}

We computed descriptive statistics and correlations of the scales used (see Tables 4, 6, and 7). Subsequently, we ran several multi-level analyses to examine the research questions. First, we replicated all findings presented by Sherman and colleagues (2015). These results are presented in the OSM B.

Second, we examined if a discriminant association pattern between situation perception and behavior could be detected. To this end, we first predicted behavior using personality traits, mean situation perceptions, as well as in situ situation perceptions (Model 1). We then examined if the findings from our re-analysis including happiness at person- and situation level could be confirmed (Model 2). Finally, we included mean positive and mean negative affect at level 2 as well as in situ positive and negative affect at level 1 as additional predictors of behavior (Model 3). The results for the level 1 and level 2 effects of situation perception are presented in Tables 9 and 10.

Sensitivity and Specificity of Predictions. Due to the large number of pre-registered hypotheses and effects reported, we computed specificity and sensitivity indices for the tests of our pre-registered hypotheses for each research question. To do so, we first classified the success of our prediction. An effect was classified as a hit (predicted to be significantly different from zero, and found significant), a correct rejection (predicted not to be significant, and found to be not significant), a miss (predicted to be significant, but found not to be significant), or a false alarm (predicted not to be significant, but found to be significant). Regarding correct rejections 
and misses, it is important to stress that within the framework of Null Hypothesis Significance Testing (NHST) the absence of a statistically significant result (e.g., $p>.10$ in our case) does not mean the effect under focus is not present. As Dienes (2014) puts it, a non-significant result can mean two things: (a) "the data might count in favor of the null", or (b) "they may count for nothing much" (p. 1). Given our power analysis as well as the pre-registration of our predictions, we would argue that our data is suitable to detect effects that are typically relevant in such designs (i.e., sample size at the within- and between-person level). A non-significant result may therefore be cautiously interpreted as evidence in favor of the null hypothesis.

Based on these assumptions, we computed sensitivity [hits / (hits + misses)] and specificity [correct rejections / (correct rejections + false alarms)]. Sensitivity then indicates how successful we could detect an effect that was hypothesized to be present, given all significant effects. Specificity indicates how successful we were at rejecting an effect that was hypothesized not to be present, given all non-significant effects. Both values lie between 0 and 1 , with a higher value indicating a better prediction. We took these values to evaluate the overall success of our predictions across studies.

\section{Results}

Descriptive statistics and correlations. Descriptive statistics and estimates for reliability of the measures used are presented in Table 4 and 6 . The reliability estimates (Cronbach's alpha) for all trait measures ranged from .70 to .86 and are comparable to the estimates presented in Study 1 (see Tables A1 and A3 in OSM A). All personality measures showed sufficient variability between participants. The intra-class correlations (ICC) were similar in magnitude across both studies. Comparing descriptive statistics from Study 1 and Study 2 (even though 
means should not be directly compared) did not reveal any striking differences that warrant further attention.

- Table $6-$

Bivariate correlations of the measures used in Study 2 are reported in Table 7. The convergent correlations of mean behavior and personality traits (i.e., the correlation of a trait score with its corresponding average behavior) were consistently higher than their discriminant correlations, pointing towards construct validity of the bipolar rating scales used for the assessment of behavior. The trait variables also correlated only moderately with the mean affect variables, again with the exception of subjective happiness which showed strong correlations to all three mean affect variables (all $|r| \mathrm{s}>$.48). Mean situation perception variables correlated moderately to highly among each other as well as with mean affect variables. Finally, mean situation variables correlated moderately with mean behavior variables. Mean affect and mean behavior also correlated moderately to highly with each other. Indeed, across the whole correlation matrix presented in Table 7, these correlations were by far the highest, pointing towards the strong nexus between aggregated affect and aggregated behavior. Overall, the pattern of correlations presented in Table 7 supports the assumption that participants responded sensibly and differentially to the items instead of just responding in a general pattern during each measurement occasion. We take this as prima facie support of the validity of the scales used.

$$
- \text { Table } 7-
$$

Exclusive link between situation perception and behavior. To examine the specificity (i.e., discriminant association patterns) of situation perception effects on behavior, behavior was predicted by the corresponding trait variables (e.g., conscientious behavior by trait conscientiousness), the mean situation variable (e.g., Duty averaged across a situations), and the 
in situ situation perception (e.g., Duty at a given moment, Model 1). This model was then extended, and happiness was included at level 1 and level 2 (Model 2), and then positive and negative affect were included at level 1 and level 2 (Model 3). We report the effects of situation perception only, but all other effects (i.e., of personality, happiness, and affect) can be found in the OSF D. The predicted effects are presented in Table 1, separately for the models with (expected for Model 2 and Model 3, lower third) and without happiness or affect (expected for Model 1, middle third).

Level 1 effects of situation perception on behavior. Table 8 displays the level 1 effects of in situ situation perception on situation to situation variations in behavior. For Model 1, we expected nearly all level 1 situation perception variables to have significant relations with in situ behavior, and our hypotheses of the non-specificity of situation characteristics for the prediction of situation to situation variations in behavior was largely confirmed. Comparable to results from Study 1 , nearly all situation characteristics were significantly related to all behavioral outcomes at level 1.

After the inclusion of happiness at level 1 (and also level 2, although this is irrelevant for the level 1 effects), we expected only theoretically coherent relations between measures of situation perception and behavior to remain significant at the within-person level (Model 2, Table 8). This was true for many cases (e.g., the effect of Intellect on Agreeableness behavior was no longer significant $(b=-0.01,90 \%$ CI $[-0.02 ; 0.00], t=-1.12)$, whereas it was significant in Model 1, without happiness at level 1 as a competing predictor $(b=-0.04,90 \%$ CI [-0.06; 0.02], $t=-3.60)$ ). For the final model (Model 3, Table 8) that included mean positive and negative affect and state positive and state negative affect as additional predictors, we expected the pre-registered effects not to change. This was true for some effects (e.g., the effect of 
situation to situation variations in Duty on situation to situation variations in conscientious behavior remained significant in all three models); however, other effects that were predicted not to be significant remained significant in the last model (e.g., the effect of Mating on agreeable behavior remained significant $(b=0.03,90 \%$ CI $[0.02 ; 0.04], t=3.99)$, although we expected it not to be significant after including affect). Although we examined effects with respect to their statistical significance, the general pattern of results can also be observed when inspecting the absolute magnitude of the effects (see Figure 3, below).

This "clearing effect" of the inclusion of happiness at state level on the discriminant association patterns of situation perception is exemplarily presented in Figure 2. On the left side of Figure 2, extraverted behavior at the within-person level can be explained with perceived Sociality (upper panel) and perceived Negativity (lower panel, both Model 1), both at state level. After including PA and NA as well as happiness at state and trait level, the effect to Sociality at state level remained significant and largely unchanged (see lower left panel in Figure 2).

- Figure 2 \& Table 8 -

Note that we also examined the variance in random slopes, that is, the person-to-person variance in how perceiving a specific situation is linked to behavior in that situation. These additional analyses and their results are reported in the online supplement OSF E.

Level 2 effects of situation perception on behavior. Similar to the effects of level 1 situation perception, we examined situation perception at level 2. Note that the effect of situation perception at level two on behavior must be understood as an effect of person to person variations in situation perception (i.e., between person effects) on person to person differences in behavior (also between person effects). All predictions were derived from Study 1. First, we again examined only situation perception at level 1 and level 2 and personality traits as a 
predictor (Model 1, Table 9). Overall, we expected fewer significant effects than at level 1. For the first model, several predicted effects remained significant, although the precision, defined via sensitivity and specificity (see below), of our predictions was overall poor. The inclusion of happiness at level 1 and level 2 (Model 2, Table 9) reduced the precision of our predictions further, as effects that were assumed to be significant were no longer significant and effects that were expected not to be significant remained substantial. Finally, the inclusion of mean positive and negative affect at level 2 (Model 3, Table 9) changed a lot of the predicted effects such that they were no longer significant, and only five expected effects remained significant. Note that more effects were significant in total, even though (based on Study 1) we did not expect them to be significant. Thus, we conclude that situation perception in general allows explaining variance in behavior, but that our predictions of these effects were rather poor; hence, the effects of mean situation perception on behavior are not yet well understood.

- Table $9-$

\section{Sensitivity and Specificity of Predictions}

Due to the large number of effects that we predicted to be either significant or not, we additionally computed the sensitivity and specificity of our predictions. Sensitivity and specificity for each research question are presented in Table 2 under Sensitivity and Specificity. The higher the sensitivity, the better we were at predicting when an effect would be significant, and the higher the specificity, the better we were at predicting when an effect would not be significant.

Level 1 effects of situation perception. Sensitivity for the predictions of Model 1 was .91, and specificity was .20. In Model 2, our sensitivity was slightly lower (.85), but specificity increased to .38. Finally, in Model 3, sensitivity decreased to .78, while specificity increased to 
.43. The results for Model 1 and Model 3 are also depicted in the upper panels of Figure 3. In Figure 3, each dot represents an unstandardized fixed effect of situation perception on behavior. Panel A displays the effects that were assumed to be significant in Model 3, and Panel B represents those effects that were assumed not to be significant in Model 3. As can be seen, those effects that were assumed to be significant in Model 3 were mainly significant, even after controlling for happiness and affect (black dots), although they were somewhat reduced in their magnitude (sensitivity of .78). For those effects that were expected not to be significant in Model 3, we found a similar pattern: After controlling for affect and happiness, several effects were indeed not significant (empty dots, specificity of .43). Notably, the effects in Panel B are also much smaller compared to those in Panel A.

- Figure $3-$

Level 2 effects of situation perception. In Model 1, the sensitivity was .61, and specificity was .50. In Model 2, sensitivity decreased to .54, while specificity slightly increased to .55 . Finally, in Model 3, sensitivity dropped substantially to .25 , while specificity remained unchanged at .55. This can also be observed in the lower two panels in Figure 3. In the left-hand Panel C, most effects that were expected to be significant were, in fact, not significant (empty dots). On the other hand, several effects of situation perception at level 2 that were expected not to be significant were, in fact, significant (Panel D, empty dots). Furthermore, the inclusion of happiness, NA, and PA did not change the effects from Model 1 to Model 3 substantially. Overall, the predictions for which effect of situation perception at level 2 would be significant and which one would not be significant were rather poor. ${ }^{5}$

\footnotetext{
${ }^{5}$ Due to the large number of effects, we also computed sensitivity and specificity after correcting for multiple tests. The results for the level 1 effects did not change substantially, whereas the predictions were even less accurate (for sensitivity, about half as accurate).
} 


\section{Discussion}

Study 2 consisted of two parts: (1) the replication of the results from Sherman and colleagues (2015), including additional analyses with affect as a competing predictor; (2) the replication and extension of the re-analysis in Study 1. First, replicating the examination of the sources of behavior (the person or the situation) did not show a similarly clear pattern as Sherman and colleagues' (2015) original study. We computed ICCs for behavior, and a high ICC means that variance of behavior must be attributed to the person rather than the current occasion. As the ICCs of situation characteristics were similar to those of affect and behavior, it cannot be concluded that behavior or affect were influenced more by the person than the perceptions of situations. However, it is important to note that all in situ measures - behavior, affect, and situation perception - did show substantial between- and within-person variance. As suggested by Baumert and colleagues (2017), we subsequently investigated this variance simultaneously instead of aggregating state measures and considering only between-person variance. As the current study showed, analyzing both within- as well as between-person variability provided a better and more nuanced picture of the relation of a person's characteristics, behaviors, feelings, and perceptions. We then replicated and extended the models examined by Sherman and colleagues (2015), predicting behavior by multiple situation characteristics as well as happiness and affect (see OSM B). These analyses showed that although situation perception and affect/happiness were substantially correlated (Horstmann \& Ziegler, 2019), both predicted unique shares of variance in behavior, both at the within- and the between-person level. Furthermore, these analyses highlighted the importance of considering in situ affect as an additional predictor of behavior, especially when examining effects of situation perception. Comparing the effects of affect measures with happiness measures revealed a possible remedy to 
the problematic overlap of situation perception and affect: The two three-item scales for positive and negative affect, which were assessed at each measurement occasion, did not substantially outperform the single item measure of state happiness and a four-item measure of trait happiness (Lyubomirsky \& Lepper, 1999; Swami et al., 2009) in terms of explained variance. Thus, a oneitem state happiness measure could be included as a good proxy for within-person fluctuations of affect, and the four-item trait measure of subjective happiness could be used to account for between-person differences in affect.

Second, we replicated our initial finding that nearly all measures of situation perception predicted nearly all forms of behavior, thereby not showing the expected discriminant association pattern. However, after including trait and state affect, the expected plausible links between situation perception and behavior, especially at the situation level, emerged. Here it is important to distinguish between level 1 and level 2 effects of situation perception: Whereas our predictions for level 1 situation perception were mainly accurate, our predictions for level 2 situation perception were comparatively poor. However, as the replication from Sherman and colleagues' (2015) original models showed (Study 2, OSM Table B2), some mean situation variables indeed explained between person variance in behavior in meaningful instances. On the contrary, personality scores included at level 2 predicted between-person variance in behavior, and situation perception scores at level 1 predicted within-person variance in behavior. Thus, personality traits may be better suited to predict between-person variance in outcomes, whereas situation perception, especially at the within-person level, may be more useful to predict withinperson variability. Nevertheless, and consistent with previous findings, we conclude that mean situation perception can also be considered a stable person-characteristic (Horstmann, Ziegler, et 
al., 2018; Ziegler \& Horstmann, 2015; Ziegler et al., 2019), but its relation to between-person differences in behavior in the context of experience sampling is not yet well understood.

\section{Limitations}

Both studies are subject to several limitations, which will be discussed below (see General Discussion, Limitations). However, some limitations are specific to Study 2. First, we used a measure of happiness as well as bipolar rating scales that were translated from English, but not validated for use in experience sampling in a German sample. Nonetheless, as indicated by the correlations between trait-scores and averaged state-scores (mean situation perception and mean happiness), scores from these measures showed good convergent and discriminant validity.

Second, we determined the a priori sample size at level $2(N \geq 250$ participants $)$ and level 1 ( $N \geq 45$ measurements). Although many participants completed 50 measurements, some participants completed fewer. This leads to a loss of test power for level 1 fixed effects and could explain why some of the effects that were expected to be significant were not. ${ }^{6}$

Finally, we deviated from the pre-registration in some minor aspects. Participants that were slow in their responses during experience sampling were not excluded as this would have meant that more than 440 measurement occasions would have had to be deleted. Based on reviewer feedback, we also excluded participants with less than four measurement occasions, instead of less than three. Further, the codebook (see pre-registration) falsely stated that some items from the experience sampling phase needed not to be recoded. However, to align the scores on level 1 with the scores on level 2 (e.g., a high score in both cases means the same thing), the items were

\footnotetext{
${ }^{6}$ Due to the large number of predicted effects, the alpha error rate is likely inflated. We therefore repeated the computation of sensitivity and specificity using a Bonferroni corrected alpha level, depending on the number of predicted non-significant effects for situation perception. Sensitivity and specificity for our predictions of the effects for level 1 situation perception remained nearly unchanged; however, sensitivity and specificity for the level 2 effects of situation perception were then even lower.
} 
recoded. The pre-registration further stated that measures of happiness should be replaced with measures of positive affect in the extended analyses - however, we did not replace the measure of happiness with positive and negative affect, but extended the models and additionally included the measures for positive and negative affect. Also, one equation in the pre-registration stated that the mean affect measures are not considered in the models, which was wrong. In line with general recommendations (Enders \& Tofighi, 2007) these variables were included as level 2 predictors to account for between-person variance in behavior. Importantly, we deviated from the pre-registration in these aspects not because "they did not work" - we changed them simply because they were wrong. We therefore think that the pre-registration is still valid, and Study 2 can be considered strictly confirmatory.

\section{General Discussion}

Across two independent studies, behavior could be predicted by situation perception, affect, happiness, and personality traits. Although affect and situation perception were correlated and shared variance with behavior in a situation, both contributed uniquely to explaining intraindividual differences in behavior. Accounting for shared variance between affect or happiness and situation perception revealed that the latter was related to behavior in logically coherent and predictable ways. These findings have important theoretical consequences for understanding and examining situation perception and its effects.

\section{Overlap of Affect and Situation Perception}

Affect and situation perception were related in the current study, and this finding is in line with previous literature (Edwards \& Templeton, 2005; Gerpott et al., 2017; Horstmann \& Ziegler, 2019; Parrigon et al., 2017). This corroborates the simple process model of situation perception, suggested by Rauthmann, Sherman, and Funder (2015). Rauthmann and colleagues 
(2015) suggested that situation perception is a product of person aspects (e.g., personality traits, social roles, affect) and situation cues. The current study showed that affect, situation perception, and personality traits are indeed related in a meaningful way among each other, but also predict unique shares of variance in behavior. More importantly, we showed that situation perception is more than just affect or happiness; situation perceptions shared systematic variance with behavior even after controlling for happiness and affect. As Rauthmann and colleagues (2015) suggested, this effect should be attributable to situation cues. Participants' ratings of a situation and the rating of their current affect was differentiable. Thus, participants' ratings distinguished between situational information (e.g., "the situation is pleasant") and their personal affect (e.g., "I am in a bad mood"). Under the assumption that all relevant person parameters could be accounted for, effects of situation perception should thus reflect situation cues and their individual processing (Colom, Bensch, Horstmann, Wehner, \& Ziegler, 2019). Controlling for individual person parameters - especially idiosyncratic person states — should, for example, increase the consensus different perceivers reach on the characteristics of a certain situation. Similarly, but only true under the assumption that affect influences situation perception (as suggested by Rauthmann et al., 2015), the perception of a situation should be more similar between two perceivers the more similar their affective states are.

The second finding of our study was that at the situation to situation level, nearly all dimensions of situation perception were tied to behavior, but that after controlling for affect, specific predicted combinations of situation characteristics and behavior emerged. This finding supports the discriminant association patterns of scores from situation perception measures. For example, after controlling for affect, perceiving a situation as intellectual was related to open behavior, but not to agreeable behavior. 
Together, our findings suggest that in situ situation perception is thus not only a powerful, but also logically coherent predictor of momentary behavior. Wilson, Thompson, and Vazire (2017) asked if "fluctuations in personality states [are] more than just fluctuations in affect?" (p. 110). The authors came to the conclusion that situations might account for additional variance after controlling for positive and negative affect for some behaviors. The current study showed that variation from situation to situation in situation perception accounted for variance in situation to situation variance in behavior, even after controlling for positive and negative affect at level 1 (and level 2). Of course, it may be possible that by accounting for further person-states (e.g., fatigue, hunger, excitement, or motivation; Rauthmann, 2016), or by considering the arousal component of affective states, effects of situation characteristics will further be reduced. Such a reduction would not be problematic as affect and situation perception are expected to be related (Horstmann \& Ziegler, 2019; Kuppens, 2009). However, if effects of situation perception on behavior were indeed fully accounted for by other affective states, then this would mean that (a) situation cues were not reflected in measures of situation perception, (b) situation cues did not affect behavior directly, and/or (c) the effects of cues on behavior were fully mediated by affective processes. However, our findings suggest that situation perceptions cannot be reduced to affect only.

\section{Happiness and Affect as Predictors of Behavior}

Even though the main purpose of the study was the investigation of situation perception, we also gained important insights into the role of trait and state happiness and affect as predictors of behavior. As mentioned earlier, a number of studies has already shown that emotions and affect explain behavior (e.g., Lench et al., 2011; Wilson et al., 2016; Wilt \& Revelle, 2017), and the results presented here further corroborate this. Affect at the person level explained between 
person variance in several behaviors across Studies 1 and 2. Nevertheless, the effects of the corresponding personality traits remained substantial (in Study 2), and affect explained additional variance previously unaccounted for. For example, in Study 2, happiness predicted conscientious, agreeable, sociable, and open behavior (see Table B2). It is possible that, as most participants were enrolled in a university during participation $(90.50 \%$ enrolled during participation, 5.84\% were at some time enrolled, and only $3.65 \%$ were never enrolled in a university), behaving conscientiously, agreeably, openly, and sociably leads to success or a feeling of accomplishment (Ziegler, Danay, Schölmerich, \& Bühner, 2010) and subsequently to more positive affect. Unfortunately, it is not possible to investigate this or any other matters related to causal forces with the current data. Thus, which behaviors affect predicts most across more heterogeneous groups of people remains a question to be addressed by future studies specifically interested in the predictive power of affect on behavior.

\section{Situation Perception, Affect, and Personality as Predictors of Behavior}

We examined how behavior could be predicted by a combination of affect, situation perception, and personality traits. Our findings support the idea of traits as density distributions of states, where the mean of the state distribution corresponds roughly to the level of the (selfreported) trait (Fleeson, 2001; Fleeson \& Gallagher, 2009; Fleeson \& Jayawickreme, 2015; Rauthmann, Horstmann, \& Sherman, 2019). Variance unaccounted for by the personality trait must thus be explained by other traits (or the same trait assessed via different measures if there is method variance), situational influences, or current affective states of the person.

Sherman and colleagues (2015) showed that "[b]oth personality traits and situation characteristics independently predicted real-time state expressions" of behavior ( p. 884). After extending and replicating their study, we conclude that personality, situation characteristics, and 
happiness or affect predict unique shares in variance in behavior. Note that affect does oftentimes not predict unique variance over happiness in behavior as the inclusion of the latter mostly reduced the effect of the former. Similar to the study by Sherman and colleagues (2015), we found that both level 1 as well as level 2 effects of situation perception predicted behavior. However, as outlined above, we were not successful in predicting which effects of mean situation perception (i.e., average between person differences in situation perception) would be significant once controlling for affect at level 2. Further, the inclusion of trait affect oftentimes reduced effects of mean situation perception. Thus, the effect of mean situation perception needs to be examined in more detail in future research. One possible avenue would be to ask participants about their "general situation experience" (Rauthmann et al., 2019) or to use a set of standardized situational vignettes to assess people's trait-like situation perception tendencies (Horstmann \& Ziegler, 2019; Ziegler et al., 2019). It will be an important next step to distinguish between stable characteristics of participants' environments and stable tendencies of a person to perceive situations, and their independent role in jointly explaining and predicting behavior (Rauthmann et al., 2019). For now, we can conclude that momentary situation perception is a good and valid predictor of in situ behavior. At the same time, the utility of between person differences in situation perception for the prediction of between person differences in behavior especially in the context of experience sampling still needs to be further examined.

\section{Implications for Personality Theories}

Sherman and colleagues (2015) discussed implications for several trait theories of personality. The current study does not alter the conclusions of Sherman and colleagues' original study but corroborates them and adds more nuance. Situations and their perceptions have a place in all personality theories (e.g., Fleeson \& Jayawickreme, 2015; McCrae \& Costa, 2008; Mischel 
\& Shoda, 1995), the exception being trait activation theory (Tett \& Guterman, 2000) which calls explicitly for person-situation interactions (Sherman et al., 2015). However, even main effects of a situation that remain after controlling for personality traits can be considered an interaction with the situation as they technically explain changes in rank-ordering among the participants that cannot be accounted for by personality traits alone (Horstmann, Ziegler, et al., 2018).

Finally, much research on situational information and influences was initially triggered by the person-situation debate (Donnellan, Lucas, \& Fleeson, 2009; Funder, 2006). Initially, the observation that personality traits explained only a limited amount of intra-individual variance in behavior (Mischel, 1968) led to the search for other viable predictors for behavior. Most researchers would now agree that both stable characteristics of the person as well as fleeting situation factors shape behavior (Funder, 2001; Mischel, Shoda, \& Mendoza-Denton, 2002; Sherman et al., 2010). Consistency can therefore be established by examining persons in certain situations: if Person X is in Situation Y, then she/he behaves extraverted (Horstmann, Rauthmann, Sherman, \& Ziegler, under review; Mischel \& Shoda, 1995; Shoda et al., 1994). However, given that momentary affect in a situation predicts behavior independently from situation characteristics and traits, momentary affect should be recognized as well in this approach: if Person X with their affective state A is in Situation Y, then they behave extraverted. The current work highlights the importance of conceptualizing the person-side in a much broader way as it was initially intended (Cattell, 1963; Horstmann, Ziegler, et al., 2018; Lewin, 1936; Rauthmann et al., 2015). If the search for behavioral consistency is to be continued, affective states of a person in a situation should also be considered explicitly in conceptualizations and tests of personality theories.

\section{The Role of Situation Perception for Appraisal Theories of Emotion}


The overlap of situation perception and affect has previously been discussed as a direct consequence of appraisal theories of emotion (Kuppens, 2009, 2015; Kuppens \& Van Mechelen, 2007; Sander et al., 2005; Scherer, 2001). The results of the current study support this idea and call for a more thorough investigation of appraisal mechanisms in situation perception. As suggested by Rauthmann and colleagues (Rauthmann, 2012; Rauthmann et al., 2015), situation perception is a result of appraisal mechanisms of cues and current affect, whereas appraisal theories of emotions state that affect results from the appraisal of situation cues (Giner-Sorolla, Kupfer, \& Sabo, 2018; Kuppens, 2009; Sander et al., 2005).

Related to this issue is the question of causality of the effects and their chronological order. Affect or emotions may shape behavior in two different ways. First, a certain emotion leads directly to a certain behavior (e.g., Lerner \& Keltner, 2001). Second, emotions serve as feedback for certain behaviors and thereby incentivize or inhibit behavior indirectly (Baumeister, Vohs, DeWall, \& Zhang, 2007; Wrzus \& Roberts, 2017). A person may select and thus perceive certain situations because they have previously led to positive feelings, or they may search for certain situations because they already experience a positive affect and would like to behave accordingly. Measuring situation perception as well as situation selection will allow investigating these processes on a more fine-grained level. At the same time, future studies that investigate the overlap of affect and situation perception must closely consider the semantic overlap in situation perception and affect items (for example pOsitivity and positive affect). Clearly, this overlap must result in a high correlation between these measures. However, due to their theoretical overlap outlined above, it may even be correct to have this overlap also reflected in their measures. The results of the current study support this idea, especially given that affect and situation perception uniquely contributed to the explanation of variance in behavior. We will 
elaborate more on this as a general problem in the Limitations section.

\section{The Examination of Personality States and Traits}

Baumert and colleagues (Baumert et al., 2017) called for the integration of personality structure, processes, and development, with the specific examination of "measures of cognitive, affective, motivational, and behavioral states under specified situational conditions" (p. 517). To examine psychological processes, these measures will need to be assessed repeatedly. The preregistration of the research questions and the methods and analyses of the current study present a starting point for such an endeavor. Furthermore, as both datasets from Study 1 and Study 2 are openly available online, researches are invited to explore and test further hypotheses.

When examining person states repeatedly, researchers face the challenge of selecting a number of constructs and items while at the same time keeping participant burden at a minimum. Based on the results of the current study, we suggest that at least one item (e.g., a bipolar rating scale) of happiness should be included in future experience sampling studies. As the correlational structure of situation characteristics has been examined extensively, future studies may also consider examining only one or two dimensions of situation perception in more detail by replacing other dimensions with measures of situation management (Rauthmann \& Sherman, 2016b) or situational affordances (Brown et al., 2015). Alternatively, of course, more refined measures of behavior, affect, and emotions could also be used, depending on the purpose of the study.

\section{Limitations}

Similar to the limitations in Sherman and colleagues' (2015) original study, the current study used a convenience sample of undergraduate students, thus limiting generalizability. At the same time, though, this enhances the closeness of the replication and allows for a better 
comparison between Study 1 and Study 2 (LeBel et al., 2017). Nevertheless, future studies should investigate if the results can be generalized across different person groups. The sample of participants also affects the sample of situations (Horstmann \& Ziegler, in press). Most of the situations that contained Duty (e.g., studying) also contained Intellect (e.g., thinking is required). Although these two dimensions are in principle independent (i.e., it is possible to imagine a situation that contains high Intellect, but little Duty, and vice versa), they were highly correlated in Study 1. Thus, for Study 2, we expected Intellect to be also related to conscientious behavior. This reflects the expectations we had about the sample that we were going to collect. Howeverand this needs to be addressed in future research — the specifics of the sample that led us to update these hypotheses are not explicitly reflected in any other quality than "being university students.” Investigating such moderator variables may be considered in future research examining person-situation-behavior contingencies. Additionally, university students (and participants in general) may only experience or report certain situations (Horstmann, Ziegler, et al., 2018), which also threatens the generalizability of the findings.

We further only tested linear relations between situation perception, affect, and behavior. However, this is by no means the only way this relation can be conceptualized and tested. It would, for example, be possible to examine cross-level interactions, predicting the betweenperson variance in random slopes of situation perception on behavior by a person's general affect. Furthermore, others have proposed non-linear interactions of persons and situation (Blum, Rauthmann, Göllner, Lischetzke, \& Schmitt, 2018; Schmitt et al., 2013), and it would hold a lot of promise to extend such models by an affective dimension.

As we have shown here, affect, behavior, and situation perception clearly overlap empirically. In some cases, however, the distinction between the three constructs (e.g., NA, 
Negativity, and Emotionality) is sometimes, to say the least, fuzzy. It may nearly be seen as trivial that the three items "I feel: happy, positive-sad negative", "The situation includes negative feelings (e.g., stress, anxiety, guilt)", and "I behave: nervous, emotional-calm, unemotional" correlate at the situation level, given their semantic overlap (i.e., similar words). Essentially, this is a chicken-and-egg problem: Do the constructs overlap because items show semantic overlap, or do the items show semantic overlap because the constructs are related? Additionally, it has to be noted that the items do not fully overlap. Instead, their relations also contain specific variance, not shared between all three measures. For example, the perception of a situation as high on Negativity shares variance with emotionality, even after controlling for happiness, as well as PA and NA $(b=0.29,90 \% \mathrm{CI}[0.26 ; 0.32], t=15.27)$. This can be considered as evidence supporting the notion of specific construct relations and not just mere semantic overlap. Nevertheless, although our data show that we were able to capture unique and systematic variance in each of these constructs, we also agree that it may be difficult to clearly state where one construct begins and the other one ends (e.g., positive affect vs. extraverted behavior). So far, this was clearly distinguished via the instruction (i.e., "how do you feel?" vs. "how do you perceive the situation?" vs. "how do you behave?"). However, we concede that the distinction between these constructs can appear somewhat vague. Two avenues for further research present themselves. First, it could be possible to generate items (or scale composites) that show less semantic overlap. Second, one could test empirically whether it is possible to design situations that speak to only one of the three constructs. Would it, for example, be possible to change a person's perception of a situation as negative, while emotionality and happiness remained unaffected? This may, for example, be possible in some professional contexts (e.g., counselling, where the consultant perceives that negative feelings are present, 
while at the same time experiences no personal negative affect). The successful discriminant experimental manipulation of a scale score can therefore be seen as further evidence for its (discriminant) validity (Borsboom, Mellenbergh, \& van Heerden, 2004; Krumm, Hüffmeier, \& Lievens, 2017). Thus, the current findings should be regarded as encouraging evidence supporting the notion of specific relations between the constructs assessed.

Finally, both studies relied on self-reports, both for the assessment of traits and states. Despite all evidence available pointing towards the validity of such assessments, no external criteria were available for external validation (e.g., peer-reports, grades, time spent studying). This is, for example, problematic with respect to the behavioral measures as they might contain wishful thinking (“how would I like to behave?") or socially desirable responding. One way to rule this out is by replacing happiness as a competing predictor with a similarly socially desirable construct. Fortunately, Sherman and colleagues (2015) also assessed state authenticity. We exploratorily replaced happiness at the state and trait level with authenticity at the state and trait level as a competing predictor. Here, however, a "clarifying effect" of authenticity on the discriminant association patterns of situation perception could not be observed ${ }^{7}$. This further corroborates the interpretation of our general pattern of findings as valid and specific to affect. Nevertheless, future studies assessing behavior, affect, and situations via other methods (e.g., smartphone use, physical arousal, geo-spatial location) will be very beneficial and advance the field in many ways.

\section{Summary and Conclusion}

What happens when a person reports their behavior in a current situation, and which other psychological variables can help explain their behavior besides personality traits? Based on the

\footnotetext{
7 The additional analyses and results can be found in the OSF G.
} 
two studies presented here, several processes seem to take place at the same time - some at the enduring level of persons (i.e., trait-like variables) and some at the momentary level (i.e., statelike variables).

First, persons act in accordance with their personality traits. Second, and distinct from personality traits, a person's general happiness explains variability in certain behaviors. The happier a person generally is, the more sociable, conscientious, and open the reported behavior within a certain time span may be. Similar to the effects of happiness, mean positive and negative affect (from repeated measurements) also predict behavior, yet this effect is not substantially different from the effects of trait happiness. Finally, mean situation perception explains behavior. Persons may possess general tendencies to perceive and interpret situations, which are reflected in their behavior. As Horstmann, Ziegler, and Ziegler (2018; Ziegler \& Horstmann, 2015; Ziegler et al., 2019) point out, assessing these tendencies—which are independent from “classic” (Big Five/Six) personality traits—may open up new avenues for personality assessments and the prediction of relevant outcomes.

At the level of time-variant person variables, there are also processes to consider. First, happiness and affect exhibited comparatively strong effects on behavior. The happier a person in a situation, the more of "the good" behaviors were displayed; being happy in a situation corresponded to behaving more honest/humble, less neurotic, more social/extraverted, more agreeable, more conscientious, more open, and also more dominant, and similar effects were found for affect. Yet, and despite these substantial effects of happiness and affect, the perception of situation characteristics still explained unique variance in behavior. A person thus responded not only based on internal, current states, but also according to perceived situation characteristics. It is striking that these interpretable effects occurred despite the short and rapid 
assessments of behavior. This indicates that these processes are at play even if a person does not consciously elaborate and examine a situation in all details. Looking only at the initial results from Study 1 and seeing that all situation characteristics were related to nearly all behaviors, one could have concluded that the situation measures do not pick up on specific situational information. However, and quite to the contrary, the analyses and results throughout Studies 1 and 2 paint a different, clearer picture: Situation perception, affect, happiness, and personality traits can be seen as sufficiently distinct predictors of behavior, each contributing uniquely to the explanation of it. Only the holistic view presented here allowed examining all aspects of withinand between-person variability (Baumert et al., 2017) and unveiling the entire picture. It remains an open question, though, how a person is capable of making these quick, distinct, and theoretically meaningful judgments in any given situation, and which processes guide these evaluations. For now, we can conclude that all of these aspects presented here play an important role in the explanation of human behavior in daily life. 


\section{References}

Arslan, R. C., \& Tata, C. (2015). formr.org survey software (Version v0.8.2). https://doi.org/10.5281/ZENODO.60957

Ashton, M. C., \& Lee, K. (2001). A theoretical basis for the major dimensions of personality. European Journal of Personality, 15(5), 327-353. https://doi.org/10.1002/per.417

Ashton, M. C., \& Lee, K. (2007). Empirical, Theoretical, and Practical Advantages of the HEXACO Model of Personality Structure. Personality and Social Psychology Review, 11(2), 150-166. https://doi.org/10.1177/1088868306294907

Baumeister, R. F., Vohs, K. D., DeWall, N. C., \& Zhang, L. (2007). How Emotion Shapes Behavior: Feedback, Anticipation, and Reflection, Rather Than Direct Causation. Personality and Social Psychology Review, 11(2), 167-203. https://doi.org/10.1177/1088868307301033

Baumert, A., Schmitt, M., Perugini, M., Johnson, W., Blum, G., Borkenau, P., ... Wrzus, C. (2017). Integrating Personality Structure, Personality Process, and Personality Development. European Journal of Personality, 31(5), 503-528. https://doi.org/10.1002/per.2115

Benjamin, D. J., Berger, J. O., Johannesson, M., Nosek, B. A., Wagenmakers, E.-J., Berk, R., ... Johnson, V. E. (2018). Redefine statistical significance. Nature Human Behaviour, 2(1), 610. https://doi.org/10.1038/s41562-017-0189-z

Bless, H., Bohner, G., Schwarz, N., \& Strack, F. (1990). Mood and Persuasion. Personality and Social Psychology Bulletin, 16(2), 331-345. https://doi.org/10.1177/0146167290162013

Blum, G. S., Rauthmann, J. F., Göllner, R., Lischetzke, T., \& Schmitt, M. (2018). The Nonlinear Interaction of Person and Situation (NIPS) Model: Theory and Empirical Evidence. European Journal of Personality, 32(3), 286-305. https://doi.org/10.1002/per.2138

Borsboom, D., Mellenbergh, G. J., \& van Heerden, J. (2004). The Concept of Validity. Psychological Review, 111(4), 1061-1071. https://doi.org/10.1037/0033-295X.111.4.1061

Brown, N. A., Neel, R., \& Sherman, R. A. (2015). Measuring the Evolutionarily Important Goals of Situations: Situational Affordances for Adaptive Problems. Evolutionary Psychology, 13(3), 1-15. https://doi.org/10.1177/1474704915593662

Campbell, D. T., \& Fiske, D. W. (1959). Convergent and discriminant validation by the multitrait-multimethod matrix. Psychological Bulletin, 56(2), 81-105. https://doi.org/10.1037/h0046016

Cattell, R. B. (1963). Personality, role, mood, and situation-perception: A unifying theory of modulators. Psychological Review, 70(1), 1-18. https://doi.org/10.1037/h0042006

Colom, R., Bensch, D., Horstmann, K. T., Wehner, C., \& Ziegler, M. (2019). Special Issue “The Ability-Personality Integration.” Journal of Intelligence, 7(2), 13. https://doi.org/10.3390/jintelligence7020013

Costa, P. T., \& McCrae, R. R. (1980). Influence of extraversion and neuroticism on subjective 
well-being: Happy and unhappy people. Journal of Personality and Social Psychology, 38(4), 668-678. https://doi.org/10.1037/0022-3514.38.4.668

Cronbach, L. J., \& Meehl, P. E. (1955). Construct validity in psychological tests. Psychological Bulletin, 52(4), 281-302. https://doi.org/10.1037/h0040957

de Vries, R. E., Tybur, J. M., Pollet, T. V., \& van Vugt, M. (2016). Evolution, situational affordances, and the HEXACO model of personality. Evolution and Human Behavior, 37(5), 407-421. https://doi.org/10.1016/j.evolhumbehav.2016.04.001

Deinzer, R., Steyer, R., Eid, M., Notz, P., Schwenkmezger, P., Ostendorf, F., \& Neubauer, A. (1995). Situational effects in trait assessment: The FPI, NEOFFI, and EPI questionnaires. European Journal of Personality, 9, 1-23. https://doi.org/10.1002/per.2410090102

Dejonckheere, E., Mestdagh, M., Houben, M., Erbas, Y., Pe, M., Koval, P., ... Kuppens, P. (2018). The bipolarity of affect and depressive symptoms. Journal of Personality and Social Psychology, 114(2), 323-341. https://doi.org/10.1037/pspp0000186

Diener, E., Oishi, S., \& Lucas, R. E. (2003). Personality, Culture, and Subjective Well-Being: Emotional and Cognitive Evaluations of Life. Annual Review of Psychology, 54(1), 403425. https://doi.org/10.1146/annurev.psych.54.101601.145056

Dienes, Z. (2014). Using Bayes to get the most out of non-significant results. Frontiers in Psychology, 5. https://doi.org/10.3389/fpsyg.2014.00781

Donnellan, M. B., Lucas, R. E., \& Fleeson, W. (2009). Introduction to personality and assessment at age 40: Reflections on the legacy of the person-situation debate and the future of person-situation integration. Journal of Research in Personality, 43(2), 117-119. https://doi.org/10.1016/j.jrp.2009.02.010

Edwards, J., \& Templeton, A. (2005). The structure of perceived qualities of situations. European Journal of Social Psycholgy, 723(35), 705-723.

Enders, C. K., \& Tofighi, D. (2007). Centering predictor variables in cross-sectional multilevel models: A new look at an old issue. Psychological Methods, 12(2), 121-138. https://doi.org/10.1037/1082-989X.12.2.121

Fleeson, W. (2001). Toward a structure- and process-integrated view of personality: Traits as density distributions of states. Journal of Personality and Social Psychology, 80(6), 10111027. https://doi.org/10.1037/0022-3514.80.6.1011

Fleeson, W. (2004). Moving personality beyond the person-situation debate. The challenge and the opportunity of within-person variability. Current Directions in Psychological Science, 13(2), 83-87. https://doi.org/10.1111/j.0963-7214.2004.00280.x

Fleeson, W. (2007). Situation-Based Contingencies Underlying Trait-Content Manifestation in Behavior. Journal of Personality, 75(4), 825-862. https://doi.org/10.1111/j.14676494.2007.00458.x

Fleeson, W., \& Gallagher, P. (2009). The implications of Big Five standing for the distribution of trait manifestation in behavior: Fifteen experience-sampling studies and a meta-analysis. Journal of Personality and Social Psychology, 97(6), 1097-1114. 
https://doi.org/10.1037/a0016786

Fleeson, W., \& Jayawickreme, E. (2015). Whole Trait Theory. Journal of Research in Personality, 56, 82-92. https://doi.org/10.1016/j.jrp.2014.10.009

Fleeson, W., Malanos, A. B., \& Achille, N. M. (2002). An intraindividual process approach to the relationship between extraversion and positive affect: Is acting extraverted as "good" as being extraverted? Journal of Personality and Social Psychology, 83(6), 1409-1422. https://doi.org/10.1037/0022-3514.83.6.1409

Fleeson, W., \& Noftle, E. E. (2008). Where does personality have its influence? A supermatrix of consistency concepts. Journal of Personality, 76(6), 1355-1386. https://doi.org/10.1111/j.1467-6494.2008.00525.x

Forgas, J. P. (2000). Affect and information processing strategies: An interactive relationship. In J. P. Forgas (Ed.), Studies in emotion and social interaction, second series. Feeling and thinking: The role of affect in social cognition (pp. 253-280). New York: Cambridge University Press.

Funder, D. C. (2001). Personality. Annual Review of Psychology, 52(1), 197-221. https://doi.org/10.1146/annurev.psych.52.1.197

Funder, D. C. (2006). Towards a resolution of the personality triad: Persons, situations, and behaviors. Journal of Research in Personality, 40(1), 21-34. https://doi.org/10.1016/j.jrp.2005.08.003

Furr, R. M. (2009). Personality psychology as a truly behavioural science. European Journal of Personality, 23(5), 369-401. https://doi.org/10.1002/per.724

Furr, R. M., \& Funder, D. C. (2004). Situational similarity and behavioral consistency: Subjective, objective, variable-centered, and person-centered approaches. Journal of Research in Personality, 38(5), 421-447. https://doi.org/10.1016/j.jrp.2003.10.001

Gasper, K., \& Clore, G. L. (2002). Attending to the Big Picture: Mood and Global Versus Local Processing of Visual Information. Psychological Science, 13(1), 34-40. https://doi.org/10.1111/1467-9280.00406

Geiser, C., Litson, K., Bishop, J., Keller, B. T., Burns, G. L., Servera, M., \& Shiffman, S. (2015). Analyzing person, situation and person $\times$ situation interaction effects: Latent state-trait models for the combination of random and fixed situations. Psychological Methods, 20(2), 165-192. https://doi.org/10.1037/met0000026

Gendolla, G. H. E. (2000). On the impact of mood on behavior: An integrative theory and a review. Review of General Psychology, 4(4), 378-408. https://doi.org/10.1037/10892680.4.4.378

Gerpott, F. H., Balliet, D., Columbus, S., Molho, C., \& de Vries, R. E. (2017). How do people think about interdependence? A multidimensional model of subjective outcome interdependence. Journal of Personality and Social Psychology. https://doi.org/10.1037/pspp0000166

Geukes, K., Nestler, S., Hutteman, R., Küfner, A. C. P., \& Back, M. D. (2017). Trait personality 
and state variability: Predicting individual differences in within- and cross-context fluctuations in affect, self-evaluations, and behavior in everyday life. Journal of Research in Personality, 69(June), 124-138. https://doi.org/10.1016/j.jrp.2016.06.003

Giner-Sorolla, R., Kupfer, T., \& Sabo, J. (2018). What Makes Moral Disgust Special? An Integrative Functional Review. Advances in Experimental Social Psychology, 57, 223-289. https://doi.org/10.1016/bs.aesp.2017.10.001

Griner, L. A., \& Smith, C. A. (2000). Contributions of Motivational Orientation to Appraisal and Emotion. Personality and Social Psychology Bulletin, 26(6), 727-740. https://doi.org/10.1177/0146167200268007

Hampel, R. (1977). Adjektiv-Skalen zur Einschätzung der Stimmung (SES). Diagnostica, 23(1), 43-60.

Holden, R. R., \& Passey, J. (2010). Socially desirable responding in personality assessment: Not necessarily faking and not necessarily substance. Personality and Individual Differences, 49(5), 446-450. https://doi.org/10.1016/j.paid.2010.04.015

Horstmann, K. T., Rauthmann, J. F., \& Sherman, R. A. (2018). Measurement of situational influences. In V. Zeigler-Hill \& T. K. Shackelford (Eds.), The SAGE Handbook of Personality and Individual Differences (pp. 465-484). SAGE Publications.

Horstmann, K. T., Rauthmann, J. F., Sherman, R. A., \& Ziegler, M. (under review). Distinguishing simple and residual consistency in functionally equivalent and nonequivalent situations: Evidence from experimental and observational longitudinal data.

Horstmann, K. T., Ziegler, J., \& Ziegler, M. (2018). Assessment of Situational Perceptions. (J. F. Rauthmann, R. Sherman, \& D. C. Funder, Eds.), The Oxford Handbook of Psychological Situations (Vol. 1). Oxford University Press. https://doi.org/10.1093/oxfordhb/9780190263348.013.21

Horstmann, K. T., \& Ziegler, M. (in press). Assessing Personality States: What to Consider when Constructing Personality State Measures. European Journal of Personality.

Horstmann, K. T., \& Ziegler, M. (2019). Situational perception and affect: Barking up the wrong tree? Personality and Individual Differences, 136, 132-139. https://doi.org/10.1016/j.paid.2018.01.020

Ioannidis, J. P. A. (2005). Why Most Published Research Findings Are False. PLoS Medicine, 2(8), e124. https://doi.org/10.1371/journal.pmed.0020124

Jones, A. B., Brown, N. A., Serfass, D. G., \& Sherman, R. A. (2017). Personality and density distributions of behavior, emotions, and situations. Journal of Research in Personality, 69, 225-236. https://doi.org/10.1016/j.jrp.2016.10.006

Judge, T. a, Simon, L. S., Hurst, C., \& Kelley, K. (2014). What I experienced yesterday is who I am today: Relationship of work motivations and behaviors to within-individual variation in the five-factor model of personality. Journal of Applied Psychology, 99(2), 199-221. https://doi.org/10.1037/a0034485

Krueger, J. I. (2009). A componential model of situation effects, person effects, and situation-by- 
person interaction effects on social behavior. Journal of Research in Personality, 43(2), 127-136. https://doi.org/10.1016/j.jrp.2008.12.042

Krumm, S., Hüffmeier, J., \& Lievens, F. (2017). Experimental Test Validation. European Journal of Psychological Assessment, 1-8. https://doi.org/10.1027/1015-5759/a000393

Kulas, J. T., \& Stachowski, A. A. (2009). Middle category endorsement in odd-numbered Likert response scales: Associated item characteristics, cognitive demands, and preferred meanings. Journal of Research in Personality, 43(3), 489-493. https://doi.org/10.1016/j.jrp.2008.12.005

Kuppens, P. (2009). The legacy of the person-situation debate for understanding variability in emotional experience. Journal of Research in Personality, 43(2), 255-256. https://doi.org/10.1016/j.jrp.2008.12.027

Kuppens, P. (2015). It's About Time: A Special Section on Affect Dynamics. Emotion Review, 7(4), 297-300. https://doi.org/10.1177/1754073915590947

Kuppens, P., \& Van Mechelen, I. (2007). Interactional appraisal models for the anger appraisals of threatened self-esteem, other-blame, and frustration. Cognition \& Emotion, 21(1), 56-77. https://doi.org/10.1080/02699930600562193

Lakens, D., Adolfi, F. G., Albers, C. J., Anvari, F., Apps, M. A. J., Argamon, S. E., ... Zwaan, R. A. (2018). Justify your alpha. Nature Human Behaviour, 2(3), 168-171. https://doi.org/10.1038/s41562-018-0311-X

Larsen, R. J. (2000). Toward a Science of Mood Regulation. Psychological Inquiry, 11(3), 129141. https://doi.org/10.1207/S15327965PLI1103_01

LeBel, E. P., Berger, D., Campbell, L., \& Loving, T. J. (2017). Falsifiability is not optional. Journal of Personality and Social Psychology, 113(2), 254-261. https://doi.org/10.1037/pspi0000106

Lee, K., \& Ashton, M. C. (2008). The HEXACO Personality Factors in the Indigenous Personality Lexicons of English and 11 Other Languages. Journal of Personality, 76(5), 1001-1054. https://doi.org/10.1111/j.1467-6494.2008.00512.x

Lench, H. C., Flores, S. a, \& Bench, S. W. (2011). Discrete emotions predict changes in cognition, judgment, experience, behavior, and physiology: A meta-analysis of experimental emotion elicitations. Psychological Bulletin, 137(5), 834-855. https://doi.org/10.1037/a0024244

Lerner, J. S., \& Keltner, D. (2001). Fear, anger, and risk. Journal of Personality and Social Psychology, 81(1), 146-159. https://doi.org/10.1037/0022-3514.81.1.146

Lewin, K. (1936). Principles of topological psychology. New York-London. New York: McGraw Hill.

Lucas, R. E., \& Fujita, F. (2000). Factors influencing the relation between extraversion and pleasant affect. Journal of Personality and Social Psychology, 79(6), 1039-1056. https://doi.org/10.1037/0022-3514.79.6.1039 
Lyubomirsky, S., \& Lepper, H. S. (1999). A measure of subjective happiness: Preliminary reliability and construct validation. Social Indicators Research, 46(2), 137-155. https://doi.org/10.1023/A:1006824100041

Mathieu, J. E., Aguinis, H., Culpepper, S. a., \& Chen, G. (2012). “Understanding and estimating the power to detect cross-level interaction effects in multilevel modeling": Correction to Mathieu, Aguinis, Culpepper, and Chen (2012). Journal of Applied Psychology, 97(5), 981981. https://doi.org/10.1037/a0029358

McCrae, R. R., \& Costa, P. T. (2008). Empirical and Theoretical Status of the Five-Factor Model of Personality Traits. In The SAGE Handbook of Personality Theory and Assessment: Volume 1 - Personality Theories and Models (pp. 273-294). London: SAGE Publications Ltd. https://doi.org/10.4135/9781849200462.n13

McNiel, J. M., \& Fleeson, W. (2006). The causal effects of extraversion on positive affect and neuroticism on negative affect: Manipulating state extraversion and state neuroticism in an experimental approach. Journal of Research in Personality, 40(5), 529-550. https://doi.org/10.1016/j.jrp.2005.05.003

Mischel, W. (1968). Personality and assessment. New York: Wiley.

Mischel, W., \& Peake, P. K. (1982). Beyond déjà vu in the search for cross-situational consistency. Psychological Review, 89(6), 730-755.

Mischel, W., \& Shoda, Y. (1995). A cognitive-affective system theory of personality: Reconceptualizing situations, dispositions, dynamics, and invariance in personality structure. Psychological Review, 102(2), 246-268.

Mischel, W., Shoda, Y., \& Mendoza-Denton, R. (2002). Situation-Behavior profiles as a locus of consistency in personality. Current Directions in Psychological Science, 11(2), 50-54. https://doi.org/10.1111/1467-8721.00166

Moors, A. (2014). Flavors of Appraisal Theories of Emotion. Emotion Review, 6(4), 303-307. https://doi.org/10.1177/1754073914534477

Moshagen, M., Hilbig, B. E., \& Zettler, I. (2014). Faktorenstruktur, psychometrische Eigenschaften und Messinvarianz der deutschsprachigen Version des 60-Item HEXACO Persönlichkeitsinventars. Diagnostica, 60(2), 86-97. https://doi.org/10.1026/00121924/a000112

Nezlek, J. B. (2017). A practical guide to understanding reliability in studies of within-person variability. Journal of Research in Personality, 69, 149-155. https://doi.org/10.1016/j.jrp.2016.06.020

Open Science Collaboration. (2015). Estimating the reproducibility of psychological science. Science, 349(6251), aac4716-aac4716. https://doi.org/10.1126/science.aac4716

Oreg, S., Edwards, J. A., \& Rauthmann, J. F. (2020). The situation six: Uncovering six basic dimensions of psychological situations from the Hebrew language. Journal of Personality and Social Psychology. https://doi.org/10.1037/pspp0000280

Oud, J. H. L., Voelkle, M. C., \& Driver, C. C. (2017). SEM Based CARMA Time Series 
Modeling for Arbitrary N. Multivariate Behavioral Research, 1-21.

https://doi.org/10.1080/00273171.2017.1383224

Ozer, D. J., \& Benet-Martínez, V. (2006). Personality and the prediction of consequential outcomes. Annual Review of Psychology, 57, 401-421. https://doi.org/10.1146/annurev.psych.57.102904.190127

Parrigon, S., Woo, S. E., Tay, L., \& Wang, T. (2017). CAPTION-ing the situation: A lexicallyderived taxonomy of psychological situation characteristics. Journal of Personality and Social Psychology, 112(4), 642-681. https://doi.org/10.1037/pspp0000111

Pervin, L. A., \& John, O. P. (1999). Handbook of personality: Theory and research. Retrieved from http://books.google.de/books?hl=de\&lr=\&id=iXMQq7wg$\mathrm{qkC} \&$ oi $=$ fnd \&pg $=\mathrm{PA} 3 \& \mathrm{dq}=\mathrm{john}+$ srivastava $+1990+$ chapter $+4 \&$ ots $=\mathrm{uD} 7391 \mathrm{jzhb} \& \mathrm{sig}=\mathrm{A} 2 \mathrm{H}$ g20cQXvoRMfMQsXCYAzLabeE

Petty, R. E., Fabrigar, L. R., \& Wegener, D. T. (2003). Emotional factors in attitudes and persuasion. In R. J. Davidson, K. R. Scherer, \& H. H. Goldsmith (Eds.), Handbook of affective sciences (pp. 72-772). Oxford: Oxford University Press.

Rauthmann, J. F. (2012). You Say the Party is Dull, I Say It is Lively: A Componential Approach to How Situations Are Perceived to Disentangle Perceiver, Situation, and Perceiver x Situation Variance. Social Psychological and Personality Science, 3(5), 519 528. https://doi.org/10.1177/1948550611427609

Rauthmann, J. F. (2015). Structuring Situational Information. European Psychologist, 20(3), 176-189. https://doi.org/10.1027/1016-9040/a000225

Rauthmann, J. F. (2016). Motivational Factors in the Perception of Psychological Situation Characteristics. Social and Personality Psychology Compass, 10(2), 92-108. https://doi.org/10.1111/spc3.12239

Rauthmann, J. F., Gallardo-Pujol, D., Guillaume, E. M., Todd, E., Nave, C. S., Sherman, R. A., ... Funder, D. C. (2014). The situational eight DIAMONDS: A taxonomy of major dimensions of situation characteristics. Journal of Personality and Social Psychology, 107(4), 677-718. https://doi.org/10.1037/a0037250

Rauthmann, J. F., Horstmann, K. T., \& Sherman, R. A. (2019). Do Self-Reported Traits and Aggregated States Capture the Same Thing? A Nomological Perspective on Trait-State Homomorphy. Social Psychological and Personality Science, 10(5), 596-611. https://doi.org/10.1177/1948550618774772

Rauthmann, J. F., Horstmann, K. T., \& Sherman, R. A. (2020). The Psychological Characteristics of Situations: Towards an Integrated Taxonomy. In J. F. Rauthmann, R. A. Sherman, \& D. C. Funder (Eds.), The Oxford Handbook of Psychological Situations. Oxford University Press. https://doi.org/10.1093/oxfordhb/9780190263348.013.19

Rauthmann, J. F., Jones, A. B., \& Sherman, R. A. (2016). Directionality of Person-Situation Transactions: Are There Spillovers Among and Between Situation Experiences And Personality States? Personality and Social Psychology Bulletin, 42(7), 893-909. https://doi.org/10.1177/0146167216647360 
Rauthmann, J. F., \& Sherman, R. A. (2016a). Measuring the Situational Eight DIAMONDS Characteristics of Situations. European Journal of Psychological Assessment, 32(2), 155164. https://doi.org/10.1027/1015-5759/a000246

Rauthmann, J. F., \& Sherman, R. A. (2016b). Situation Change: Stability and Change of Situation Variables between and within Persons. Frontiers in Psychology, 6. https://doi.org/10.3389/fpsyg.2015.01938

Rauthmann, J. F., \& Sherman, R. A. (2016c). Ultra-Brief Measures for the Situational Eight DIAMONDS Domains. European Journal of Psychological Assessment, 32(2), 165-174. https://doi.org/10.1027/1015-5759/a000245

Rauthmann, J. F., \& Sherman, R. A. (2018a). The description of situations: Towards replicable domains of psychological situation characteristics. Journal of Personality and Social Psychology, 114, 482-488.

Rauthmann, J. F., \& Sherman, R. A. (2018b). Toward a Research Agenda for the Study of Situation Perceptions: A Variance Componential Framework. Personality and Social Psychology Review, 114(3), 482-488. https://doi.org/10.1037/pspp0000162

Rauthmann, J. F., Sherman, R. A., \& Funder, D. C. (2015). Principles of Situation Research: Towards a Better Understanding of Psychological Situations. European Journal of Personality, 29(3), 363-381. https://doi.org/10.1002/per.1994

Read, S. J., Smith, B. J., Droutman, V., \& Miller, L. C. (2017). Virtual personalities: Using computational modeling to understand within-person variability. Journal of Research in Personality, 69, 237-249. https://doi.org/10.1016/j.jrp.2016.10.005

Roberts, B. W., Kuncel, N. R., Shiner, R., Caspi, A., \& Goldberg, L. R. (2007). The Power of Personality: The Comparative Validity of Personality Traits, Socioeconomic Status, and Cognitive Ability for Predicting Important Life Outcomes. Perspectives on Psychological Science, 2(4), 313-345. https://doi.org/10.1111/j.1745-6916.2007.00047.x

Russell, J. A. (2003). Core affect and the psychological construction of emotion. Psychological Review, 110(1), 145-172. https://doi.org/10.1037/0033-295X.110.1.145

Russell, J. A., \& Barrett, L. F. (1999). Core affect, prototypical emotional episodes, and other things called emotion: Dissecting the elephant. Journal of Personality and Social Psychology, 76(5), 805-819. https://doi.org/10.1037/0022-3514.76.5.805

Sander, D., Grandjean, D., \& Scherer, K. R. (2005). A systems approach to appraisal mechanisms in emotion. Neural Networks, 18(4), 317-352. https://doi.org/10.1016/j.neunet.2005.03.001

Scherer, K. R. (2001). Appraisal considered as a process of multi-level sequential checking. In K. R. Scherer, A. Schorr, \& T. Johnstone (Eds.), Appraisal processes in emotion: Theory, methods, research (pp. 92-120). New York: Oxford University Press.

Schmitt, M., Gollwitzer, M., Baumert, A., Blum, G., Gschwendner, T., Hofmann, W., \& Rothmund, T. (2013). Proposal of a Nonlinear Interaction of Person and Situation (NIPS) model. Frontiers in Psychology, 4. https://doi.org/10.3389/fpsyg.2013.00499 
Serfass, D. G., \& Sherman, R. A. (2013). Personality and perceptions of situations from the Thematic Apperception Test. Journal of Research in Personality, 47(6), 708-718. https://doi.org/10.1016/j.jrp.2013.06.007

Sherman, R. A., Nave, C. S., \& Funder, D. C. (2010). Situational similarity and personality predict behavioral consistency. Journal of Personality and Social Psychology, 99(2), 330343. https://doi.org/10.1037/a0019796

Sherman, R. A., Nave, C. S., \& Funder, D. C. (2012). Properties of persons and situations related to overall and distinctive personality-behavior congruence. Journal of Research in Personality, 46(1), 87-101. https://doi.org/10.1016/j.jrp.2011.12.006

Sherman, R. A., Rauthmann, J. F., Brown, N. A., Serfass, D. G., \& Jones, A. B. (2015). The independent effects of personality and situations on real-time expressions of behavior and emotion. Journal of Personality and Social Psychology, 109(5), 872-888. https://doi.org/10.1037/pspp0000036

Shoda, Y., \& Mischel, W. (2000). Reconciling contextualism with the core assumptions of personality psychology. European Journal of Personality, 14, 407-428. https://doi.org/10.1002/1099-0984(200009/10)14:5<407::AID-PER391>3.0.CO;2-3

Shoda, Y., Mischel, W., \& Wright, J. C. (1994). Intraindividual stability in the organization and patterning of behavior: Incorporating psychological situations into the idiographic analysis of personality. Journal of Personality and Social Psychology, 67(4), 674-687. Retrieved from http://www.ncbi.nlm.nih.gov/pubmed/7965613

Siegling, A. B., Petrides, K. V., \& Martskvishvili, K. (2015). An Examination of a New Psychometric Method for Optimizing Multi-Faceted Assessment Instruments in the Context of Trait Emotional Intelligence. European Journal of Personality, 29(1), 42-54. https://doi.org/10.1002/per.1976

Siemer, M. (2009). Mood Experience: Implications of a Dispositional Theory of Moods. Emotion Review, 1(3), 256-263. https://doi.org/10.1177/1754073909103594

Simmons, J. P., Nelson, L. D., \& Simonsohn, U. (2011). False-Positive Psychology: Undisclosed Flexibility in Data Collection and Analysis Allows Presenting Anything as Significant. Psychological Science, 22(11), 1359-1366. https://doi.org/10.1177/0956797611417632

Soto, C. J. (2019). How Replicable Are Links Between Personality Traits and Consequential Life Outcomes? The Life Outcomes of Personality Replication Project. Psychological Science, 30(5), 711-727. https://doi.org/10.1177/0956797619831612

Steyer, R., Mayer, A., Geiser, C., \& Cole, D. A. (2015). A Theory of States and Traits-Revised. Annual Review of Clinical Psychology, 11(1), 71-98. https://doi.org/10.1146/annurevclinpsy-032813-153719

Steyer, R., Schmitt, M., \& Eid, M. (1999). Latent state-trait theory and research in personality and individual differences. European Journal of Personality, 13, 389-408. Retrieved from http://onlinelibrary.wiley.com/doi/10.1002/(SICI)10990984(199909/10)13:5\%3C389::AID-PER361\%3E3.0.CO;2-A/abstract

Swami, V., Stieger, S., Voracek, M., Dressler, S. G., Eisma, L., \& Furnham, A. (2009). 
Psychometric Evaluation of the Tagalog and German Subjective Happiness Scales and a Cross-Cultural Comparison. Social Indicators Research, 93(2), 393-406.

https://doi.org/10.1007/s11205-008-9331-7

Tackett, J. L., Lilienfeld, S. O., Patrick, C. J., Johnson, S. L., Krueger, R. F., Miller, J. D., ... Shrout, P. E. (2017). It's Time to Broaden the Replicability Conversation: Thoughts for and From Clinical Psychological Science. Perspectives on Psychological Science, 12(5), 742756. https://doi.org/10.1177/1745691617690042

Tett, R. P., \& Guterman, H. A. (2000). Situation trait relevance, trait expression, and crosssituational consistency: Testing a principle of trait activation. Journal of Research in Personality, 34(4), 397-423. https://doi.org/10.1006/jrpe.2000.2292

Verduyn, P., Delvaux, E., Van Coillie, H., Tuerlinckx, F., \& Van Mechelen, I. (2009). Predicting the duration of emotional experience: Two experience sampling studies. Emotion, 9(1), 8391. https://doi.org/10.1037/a0014610

Wald, A. (1943). Tests of statistical hypotheses concerning several parameters when the number of observations is large. Transactions of the American Mathematical Society, 54(3), 426483. Retrieved from http://www.jstor.org/stable/1990256

Watson, D., \& Gray, E. K. (2007). Assessing positive and negative affect via self-report. In J. A. Coan \& J. J. B. Allen (Eds.), Handbook of emotion elicitation and assessment (pp. 171183). New York, NY, US: Oxford University Press.

Watson, D., \& Tellegen, A. (1985). Toward a consensual structure of mood. Psychological Bulletin, 98(2), 219-235. https://doi.org/10.1037/0033-2909.98.2.219

Weidman, A. C., Steckler, C. M., \& Tracy, J. L. (2017). The jingle and jangle of emotion assessment: Imprecise measurement, casual scale usage, and conceptual fuzziness in emotion research. Emotion, 17(2), 267-295. https://doi.org/10.1037/emo0000226

Wilson, R. E., Thompson, R. J., \& Vazire, S. (2017). Are fluctuations in personality states more than fluctuations in affect? Journal of Research in Personality, 69, 110-123. https://doi.org/10.1016/j.jrp.2016.06.006

Wilt, J. A., Bleidorn, W., \& Revelle, W. (2017). Velocity explains the links between personality states and affect. Journal of Research in Personality, 69, 86-95. https://doi.org/10.1016/j.jrp.2016.06.008

Wilt, J. A., \& Revelle, W. (2017). The Big Five, everyday contexts and activities, and affective experience. Personality and Individual Differences. https://doi.org/10.1016/j.paid.2017.12.032

Winkielman, P., Knutson, B., Paulus, M., \& Trujillo, J. L. (2007). Affective influence on judgments and decisions: Moving towards core mechanisms. Review of General Psychology, 11(2), 179-192. https://doi.org/10.1037/1089-2680.11.2.179

Wrzus, C., \& Roberts, B. W. (2017). Processes of Personality Development in Adulthood: The TESSERA Framework. Personality and Social Psychology Review, 21(3), 253-277. https://doi.org/10.1177/1088868316652279 
Wyer, R. S., Clore, G. L., \& Isbell, L. M. (1999). Affect and Information Processing. In M. P. Zanna (Ed.), Advances in Experimental Social Psychology (pp. 1-77). Academic Press.

Yik, M. S. M., Russell, J. A., \& Barrett, L. F. (1999). Structure of self-reported current affect: Integration and beyond. Journal of Personality and Social Psychology, 77(3), 600-619. https://doi.org/10.1037/0022-3514.77.3.600

Ziegler, M., \& Bäckström, M. (2016). 50 Facets of a Trait - 50 Ways to Mess Up? European Journal of Psychological Assessment, 32(2), 105-110. https://doi.org/10.1027/10155759/a000372

Ziegler, M., \& Buehner, M. (2009). Modeling Socially Desirable Responding and Its Effects. Educational and Psychological Measurement, 69(4), 548-565. https://doi.org/10.1177/0013164408324469

Ziegler, M., Danay, E., Schölmerich, F., \& Bühner, M. (2010). Predicting academic success with the big 5 rated from different points of view: Self-rated, other rated and faked. European Journal of Personality, 24, 341-355. https://doi.org/10.1002/per.753

Ziegler, M., \& Horstmann, K. T. (2015). Discovering the Second Side of the Coin. European Journal of Psychological Assessment, 31(2), 69-74. https://doi.org/10.1027/1015$5759 / \mathrm{a} 000258$

Ziegler, M., Horstmann, K. T., \& Ziegler, J. (2019). Personality in situations: Going beyond the OCEAN and introducing the Situation Five. Psychological Assessment, 31(4), 567-580. https://doi.org/10.1037/pas0000654 
Table 1

Predicted Effects for Situation Perception in Study 1 and Study 2

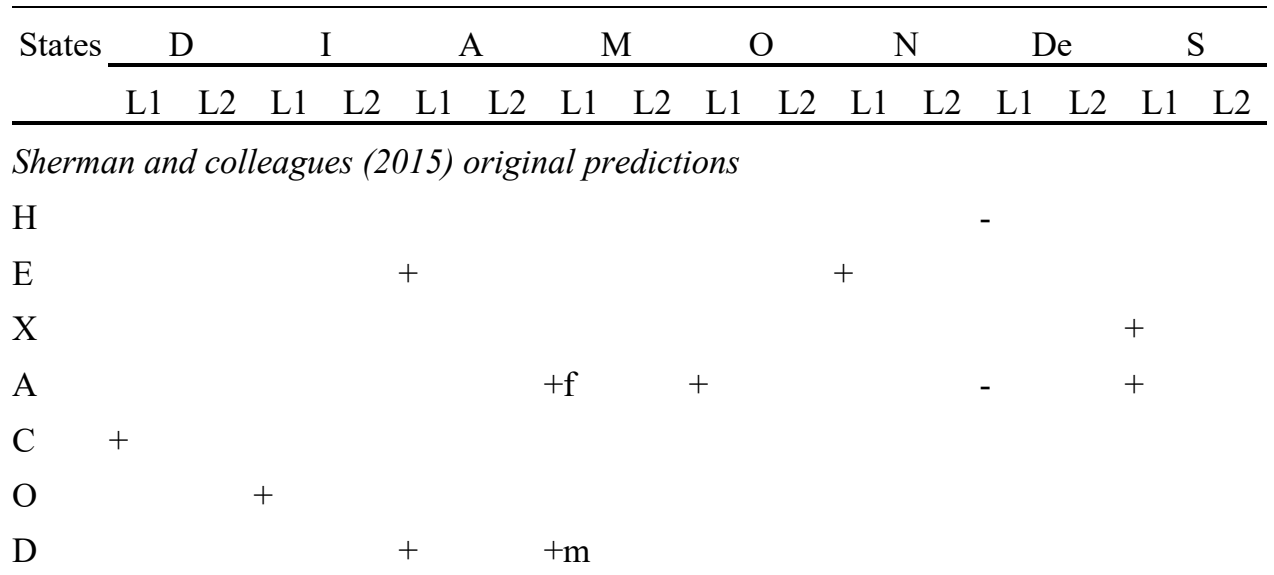

Study 2: Prediction for the effects in Model 1

$\begin{array}{lllllllllllllllll}\mathrm{H} & - & - & & - & - & & & + & + & - & - & - & - & + & \\ \mathrm{E} & + & + & + & + & + & & & - & - & + & + & + & + & - & \\ \mathrm{X} & - & - & - & - & - & - & + & & + & + & - & - & - & - & + & + \\ \mathrm{A} & - & - & - & - & - & + & & + & + & - & - & - & - & + & + \\ \mathrm{C} & + & + & & - & - & & & & & & - & - & - & + & \\ \mathrm{O} & + & + & & - & - & + & & + & + & - & - & - & - & +\end{array}$

Study 2: Predictions for the effects in Models 2 and 3

\begin{tabular}{llllllllllllllll}
$\mathrm{H}$ & & & & - & - & & & & + & & - & - & - & \\
$\mathrm{E}$ & & + & + & + & & & - & - & + & + & + & + & \\
$\mathrm{X}$ & & - & & & + & & + & + & - & - & & - & + & + \\
$\mathrm{A}$ & & & - & - & - & & - & + & + & - & - & - & - & + \\
$\mathrm{C}$ & + & + & & - & - & & & - & & + & - & & - & + \\
$\mathrm{O}$ & + & + & & - & - & & - & & & & - & & - & \\
\hline
\end{tabular}

Note. $\mathrm{L} 1=$ expected effects at level 1; L2 = expected effects on level 2; Model 1: Predicting behavior from situation perception at level 1 and level 2. Model 2: Predicting behavior from situation perception at level 2 and level 2, and Happiness at level 1 and level 2. Model 3: Predicting behavior from situation perception at level 2 and level 2, Happiness on level 1 and level 2, and PA (positive affect) and NA (negative affect) at level 1 and level 2. For detailed descriptions of the models, see Table 3.

$+=$ a positive effect was expected; - = a negative effect was expected; empty cells indicate that no effect was expected. $+m$ and $+f$ means that the effect was initially (Sherman et al., 2015) predicted to be statistically significant only for males and females, respectively.

Situation perception (columns): $\mathrm{D}=$ Duty; $\mathrm{I}=$ Intellect; $\mathrm{A}=$ Adversity; $\mathrm{M}=$ Mating; $\mathrm{O}=$ pOsitivity; $\mathrm{N}$ = Negativity; $\mathrm{De}=$ Deception; $\mathrm{S}=$ Sociality .

Behavior (rows): $\mathrm{H}=$ Honesty/Humility; $\mathrm{E}=$ Emotionality; $\mathrm{X}=\mathrm{eX}$ traversion (Sociability aspect); $\mathrm{A}=$ Agreeableness; $\mathrm{O}=$ Openness; $\mathrm{D}=$ Dominance. Note that Dominance was not included in Study 2 (lower thirds of the table), as we overlooked it in the re-analysis in Study 1 and did not pre-register any hypotheses concerning Dominance. 
Table 2

Overview of Research Questions, Analyses, and Results

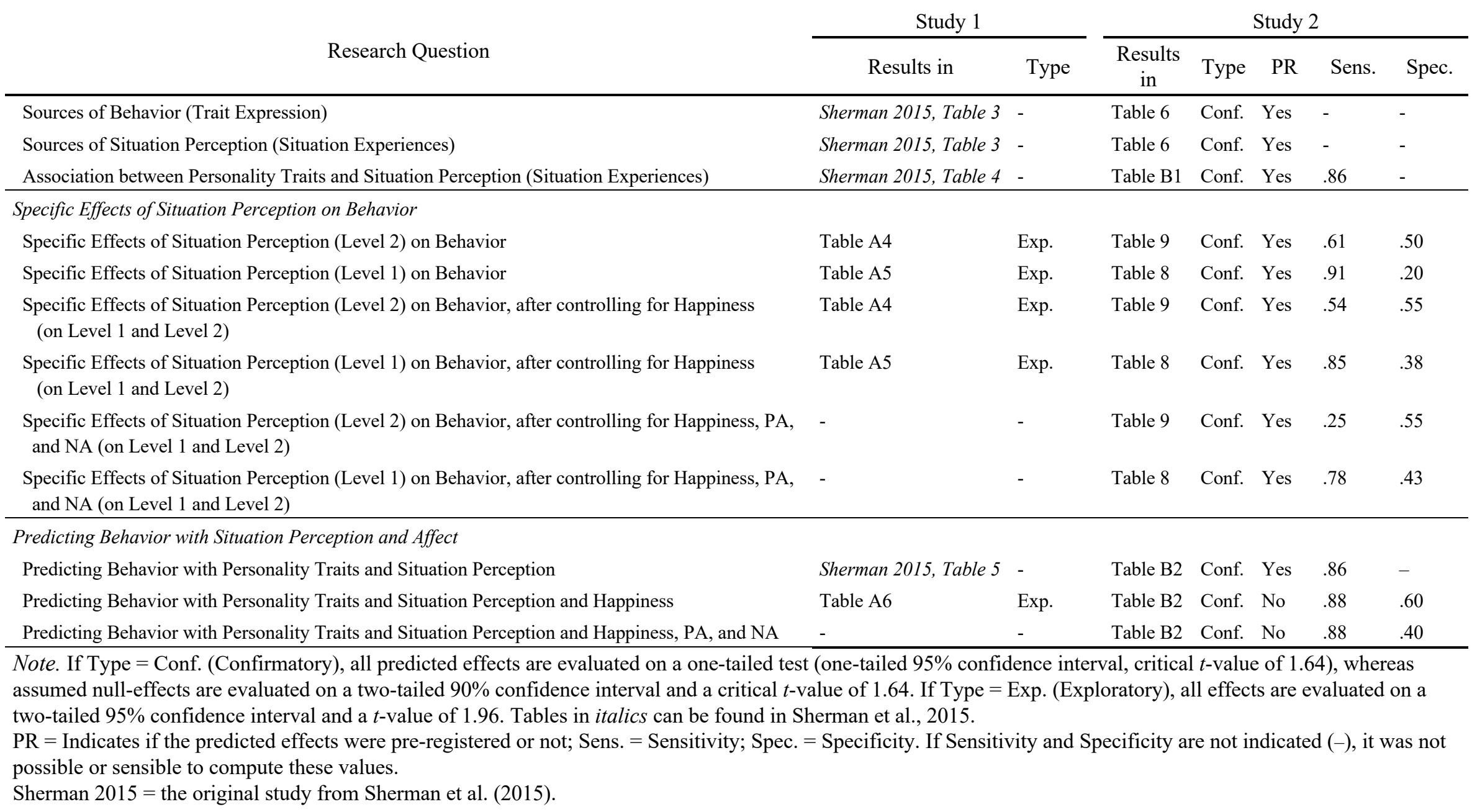


Table 3

Simple Notation of Multi-Level Models Analyzed in Study 2

\begin{tabular}{|c|c|c|}
\hline Research Questions & Model & Name \\
\hline $\begin{array}{l}\text { - Can behavior be predicted by situation perception and } \\
\text { personality? } \\
\text { - Are the links between situation perception and } \\
\text { behavior exclusive? } \\
\text { - Does personality predict behavior? }\end{array}$ & $b_{L 1}=P_{L 2}+S_{L 2}+s_{L 1}$ & Model 1 \\
\hline $\begin{array}{l}\text { - Are the links between situation perception and } \\
\text { behavior exclusive after controlling for happiness at } \\
\text { level land level } 2 \text { ? }\end{array}$ & $\begin{array}{l}b_{L 1}=P_{L 2}+S_{L 2}+S_{L 1} \\
+S H S_{L 2}+h_{L 1}\end{array}$ & Model 2 \\
\hline $\begin{array}{l}\text { - Are the links between situation perception and } \\
\text { behavior exclusive after controlling for happiness, PA, } \\
\text { and NA at level } 1 \text { and level } 2 \text { ? } \\
\text { - Do PA and NA, on person and situation level, predict } \\
\text { behavior? }\end{array}$ & $\begin{array}{l}b_{L 1}=P_{L 2}+S_{L 2}+s_{L 1} \\
+S H S_{L 2}+h_{L 1} \\
+N A_{L 2}+P A_{L 2}+n a_{L 1}+n a_{L 1}\end{array}$ & Model 3 \\
\hline \multicolumn{3}{|c|}{$\begin{array}{l}\text { Note. } b=\text { behavior; } P=\text { personality trait; } S=\text { mean situation perception, } s=\text { in situ, state situation } \\
\text { perception; } S H S=\text { trait subjective happiness; } h=\text { state happiness; } N A=\text { mean negative affect, } P A=\text { mean } \\
\text { positive affect, } n a=\text { state negative affect, } p a=\text { state positive affect; } L 1=\text { variable included at level } 1 \text {, the } \\
\text { state, occasion, or situation level; } L 2=\text { predictor included at level } 2 \text {, the person level. A detailed } \\
\text { mathematical description of the multilevel-models, following Snijders' and Bosker's (1999) notation, can } \\
\text { be found in the OSF C. We assumed random intercepts and random slopes for all models tested. For } \\
\text { model 3, we additionally compared a random intercept, random slopes vs. a random intercept, fixed } \\
\text { slopes model for situation perception, indicating that the random slopes model is generally the more } \\
\text { appropriate model (see OSF). }\end{array}$} \\
\hline
\end{tabular}


Unveiling an Exclusive Link 64

Table 4

Descriptive Statistics of Scales and Items at Person level (trait, mean state) in Study 2

\begin{tabular}{|c|c|c|c|c|c|c|}
\hline Variables & Sample Item/Adjective & $n$ & $M$ & $S D$ & Range & $\alpha$ \\
\hline \multicolumn{7}{|l|}{$\overline{\text { Trait Variables }}$} \\
\hline \multicolumn{7}{|l|}{ Personality } \\
\hline Honesty/Humility & Having a lot of money is not especially important to me. & 254 & 4.09 & 0.77 & $1.00-5.90$ & .70 \\
\hline Emotionality & I sometimes can't help worrying about little things. & 254 & 3.85 & 0.84 & $1.10-5.80$ & .79 \\
\hline Extraversion & $\begin{array}{l}\text { In social situations, I'm usually the one who makes the first } \\
\text { move. }\end{array}$ & 254 & 3.81 & 0.86 & $1.30-5.60$ & .80 \\
\hline Agreeableness & Most people tend to get angry more quickly than I do & 254 & 3.75 & 0.75 & $1.60-5.40$ & .75 \\
\hline Conscientiousness & I often push myself very hard when trying to achieve a goal. & 254 & 4.16 & 0.83 & $1.80-5.90$ & .83 \\
\hline Openness & People have often told me that I have a good imagination. & 254 & 4.42 & 0.78 & $1.90-6.00$ & .73 \\
\hline \multicolumn{7}{|l|}{ Happiness } \\
\hline Subjective Happiness & $\begin{array}{l}\text { In general, I consider myself: not a happy person - a very } \\
\text { happy person. }\end{array}$ & 254 & 5.19 & 1.37 & $1.75-8.00$ & .86 \\
\hline \multicolumn{7}{|l|}{ Mean State Variables } \\
\hline \multicolumn{7}{|l|}{ Behavior } \\
\hline Honesty/Humility & humble, honest_arrogant, dishonest & 254 & 6.18 & 0.83 & $1.90-8.00$ & - \\
\hline Emotionality & nervous, emotional_calm, unemotional & 254 & 4.04 & 1.02 & $1.42-7.25$ & - \\
\hline Sociability & outgoing, sociable-reserved, quiet & 254 & 5.25 & 0.85 & $2.67-7.55$ & - \\
\hline Dominance & dominant, assertive—submissive, unassertive & 254 & 5.16 & 0.79 & $2.50-7.80$ & - \\
\hline Agreeableness & warm, agreeable - cold, quarrelsome & 254 & 6.16 & 0.81 & $3.31-8.00$ & - \\
\hline Conscientiousness & organized, hardworking—disorganized, lazy & 254 & 5.19 & 0.92 & $1.72-7.46$ & - \\
\hline Openness & intelligent, creative- unintelligent, uncreative & 254 & 5.38 & 0.89 & $2.6-8.00$ & - \\
\hline \multicolumn{7}{|l|}{ Situation Perception } \\
\hline Duty & Work has to be done. & 254 & 4.45 & 1.34 & $1.00-7.97$ & - \\
\hline Intellect & Deep thinking is required. & 254 & 3.82 & 1.25 & $1.10-7.88$ & - \\
\hline Adversity & Someone is being threatened, blamed, or criticized. & 254 & 1.58 & 0.67 & $1.00-5.58$ & - \\
\hline Mating & Potential romantic partners are present. & 254 & 2.57 & 1.42 & $1.00-8.00$ & - \\
\hline pOsitivity & Situation is enjoyable. & 254 & 4.56 & 0.99 & $1.63-7.50$ & - \\
\hline \multirow[t]{2}{*}{ Negativity } & Situation includes negative feelings (e.g., stress, anxiety, guilt). & & & & & \\
\hline & & 254 & 3.12 & 1.22 & $1.00-7.43$ & - \\
\hline Deception & Someone is being deceived. & 254 & 1.38 & 0.65 & $1.00-6.00$ & \\
\hline Sociality & Social interaction is possible or required. & 254 & 4.28 & 1.24 & $1.33-7.79$ & - \\
\hline \multicolumn{7}{|l|}{ Happiness } \\
\hline $\begin{array}{l}\text { Subjective Happiness } \\
\text { Affect }\end{array}$ & \multicolumn{5}{|c|}{ Affect } & - \\
\hline Positive Affect & lustig [funny] - Study 2 only & 254 & 4.19 & 0.98 & $1.71-6.94$ & .78 \\
\hline Negative Affect & gereizt [irrtated] - Study 2 only & 254 & 2.35 & 0.88 & $1.00-5.58$ & .83 \\
\hline
\end{tabular}

Note. $\alpha=$ Cronbach's alpha for the trait-scales and nested alpha (Nezlek, 2017) for the state measures of affect. Alpha could not be computed for scales that were assessed with one item only during state assessment. 
Table 5

Differences between Study 1 and Study 2

\begin{tabular}{|c|c|c|c|}
\hline Design Facet & Study 1 & Study 2 & Explanation/Reason \\
\hline Language & English & German & \\
\hline Physical setting & Florida/USA & Berlin/Germany & \\
\hline \multicolumn{4}{|l|}{ Method } \\
\hline \multicolumn{4}{|l|}{ Likert Scale Used } \\
\hline Subjective Happiness Scale & $1-7$ & $1-8$ & $\begin{array}{l}\text { Avoid middle category, } \\
\text { increase variance }\end{array}$ \\
\hline ESM assessment & $1-7$ & $1-8$ & $\begin{array}{l}\text { Avoid middle category, } \\
\text { increase variance }\end{array}$ \\
\hline \multicolumn{4}{|l|}{ Number of Items } \\
\hline Trait/Personality assessment & 60 & 80 (some optional) & $\begin{array}{l}\text { Not all relevant for } \\
\text { replication }\end{array}$ \\
\hline ESM assessment & 18 & 25 (some optional) & $\begin{array}{l}\text { Added six items for affect, } \\
\text { geo-position, removed self- } \\
\text { esteem and authenticity }\end{array}$ \\
\hline \multicolumn{4}{|l|}{ Procedure } \\
\hline Participant recruitment & Campus, students & E-mail list to students & \\
\hline Participant briefing & In laboratory & Online & \\
\hline Remuneration & Money (270USD) & Course credit, feedback & No money available \\
\hline Trait assessment & In lab & Online & Easier to conduct \\
\hline ESM assessment & Sms & E-mail & No money for sms available \\
\hline Presentation of ESM Items & Randomized & Same order & \\
\hline $\begin{array}{l}\text { Exclusion of measurement } \\
\text { occasions }\end{array}$ & $\begin{array}{l}\text { If participants did not } \\
\text { respond within one } \\
\text { hour }\end{array}$ & $\begin{array}{l}\text { If participants were too } \\
\text { quick (i.e., less than } 10 \\
\text { sec.) }\end{array}$ & $\begin{array}{l}\text { Time after invitation not } \\
\text { tracked, not assumed to be } \\
\text { relevant }\end{array}$ \\
\hline Average Number ESM Assessments & $M=46.44, S D=9.61$ & $M=30.19, S D=17.43$ & \\
\hline \multicolumn{4}{|c|}{ Analysis } \\
\hline exclusion of participants & $\begin{array}{l}\text { Not responded within } \\
\text { one hour }\end{array}$ & $\begin{array}{l}\text { Less than } 4 \text { measurement } \\
\text { occasions }\end{array}$ & \\
\hline Significance level & .05 & $\begin{array}{l}.10 \text { for expected non- } \\
\text { significant effects, } .05, \\
\text { one-tailed for predicted } \\
\text { effects }\end{array}$ & \\
\hline \multicolumn{4}{|l|}{ Sample characteristics } \\
\hline Sample size & 209 & 274 & $\begin{array}{l}\text { Power-analyses, at least } N= \\
250\end{array}$ \\
\hline male/female ratio & $136 / 73$ & $41 / 231$ & \\
\hline Age & $M=18.61, S D=1.78$ & $M=24.22, S D=6.35$ & \\
\hline
\end{tabular}


Table 6

Results from Random-Intercept Only Models for Behavior, Situation Perception, Affect and Happiness in Study 2

\begin{tabular}{|c|c|c|c|c|c|}
\hline Scales & $\boldsymbol{T}_{00}$ & $\sigma$ & ICC & intercept & $n$ \\
\hline Behavior & 0.53 & 1.79 & .23 & 6.17 & 7611 \\
\hline Honesty/Humility & 0.69 & 2.70 & .20 & 5.20 & 7617 \\
\hline \multicolumn{6}{|l|}{ Emotionality } \\
\hline eXtraversion & 0.54 & 1.45 & .27 & 5.17 & 7614 \\
\hline Sociability & 0.56 & 2.59 & .18 & 5.27 & 7612 \\
\hline Dominance & 0.63 & 1.29 & .33 & 6.18 & 7620 \\
\hline Agreeableness & 0.87 & 2.82 & .24 & 4.04 & 7636 \\
\hline Conscientiousness & 0.69 & 1.98 & .26 & 5.38 & 7617 \\
\hline \multicolumn{6}{|l|}{ Openness } \\
\hline Situation Perception & 1.38 & 5.68 & .20 & 4.44 & 7654 \\
\hline Duty & 1.28 & 4.41 & .22 & 3.81 & 7642 \\
\hline Intellect & 0.34 & 1.48 & .19 & 1.57 & 7657 \\
\hline Adversity & 1.71 & 4.53 & .27 & 2.57 & 7650 \\
\hline Mating & 0.73 & 2.99 & .20 & 4.58 & 7648 \\
\hline pOsitivity & 1.25 & 3.15 & .28 & 3.10 & 7653 \\
\hline Negativity & 0.33 & 0.85 & .28 & 1.37 & 7639 \\
\hline Deception & 1.10 & 5.90 & .16 & 4.29 & 7652 \\
\hline \multicolumn{6}{|l|}{ Sociality } \\
\hline Happiness & 0.73 & 2.30 & .24 & 5.68 & 7632 \\
\hline \multicolumn{6}{|l|}{ Subjective Happiness } \\
\hline Affect & 0.83 & 2.18 & .28 & 4.20 & 7663 \\
\hline Positive Affect & 0.62 & 1.70 & .27 & 2.32 & 7663 \\
\hline Negative Affect & 0.53 & 1.79 & .23 & 6.17 & 7611 \\
\hline
\end{tabular}

Note. $N=241$ to $270 . \boldsymbol{\tau}_{00}=$ Variance between intercepts (i.e., between-person variance in random intercept only model); $\sigma=$ Variance around intercepts (within-person variance). ICC $=$ intra-class correlation, proportion of between person variance per total variance (within- and between-person variance; i.e., the higher the value, the more is the variance attributable to the person), Intercept = fixed effect for intercept in random-intercept only model, corresponds to the across-person mean). Random-Intercept Only Models do not assume any predictor. 
Unveiling an Exclusive Link 67

Table 7

Bivariate Pearson-Correlations of Trait Variables and Mean State Variables in Study 2

\begin{tabular}{|c|c|c|c|c|c|c|c|c|c|c|c|c|c|c|c|c|c|c|c|c|c|c|c|c|c|c|c|}
\hline \multirow[b]{2}{*}{ Variable } & \multirow[b]{2}{*}{$M$} & \multirow[b]{2}{*}{$S D$} & \multicolumn{7}{|c|}{ Trait } & \multicolumn{8}{|c|}{ Mean situation perception } & \multicolumn{3}{|c|}{ Mean affect } & \multicolumn{7}{|c|}{ Mean behavior } \\
\hline & & & $\mathrm{H}$ & $\bar{E}$ & $\mathrm{X}$ & $\mathrm{A}$ & $\mathrm{C}$ & $\mathrm{O}$ & $\overline{\text { SHS }}$ & $\mathrm{D}$ & I & $\mathrm{A}$ & $\mathrm{M}$ & $\mathrm{O}$ & $\mathrm{N}$ & $\mathrm{D}$ & $\bar{S}$ & PA & NA & $\overline{\text { SHS }}$ & $\mathrm{H}$ & $\bar{E}$ & $\mathrm{XS}$ & $\mathrm{XD}$ & $\mathrm{A}$ & $\mathrm{C}$ & $\overline{\mathrm{O}}$ \\
\hline \multicolumn{28}{|l|}{$\overline{\text { Trait variables }}$} \\
\hline Honesty/Humility & 4.09 & 0.77 & - & & & & & & & & & & & & & & & & & & & & & & & & \\
\hline Emotionality & 3.85 & 0.84 & .11 & - & & & & & & & & & & & & & & & & & & & & & & & \\
\hline eXtraversion & 3.81 & 0.86 & .03 & -.14 & - & & & & & & & & & & & & & & & & & & & & & & \\
\hline Agreeableness & 3.75 & 0.75 & .22 & .00 & .01 & - & & & & & & & & & & & & & & & & & & & & & \\
\hline Conscientiousness & 4.16 & 0.83 & .09 & .10 & -.02 & -.04 & - & & & & & & & & & & & & & & & & & & & & \\
\hline Openness & 4.42 & 0.78 & -.02 & -.12 & .27 & -.04 & .02 & - & & & & & & & & & & & & & & & & & & & \\
\hline Subjective Happiness & 5.19 & 1.37 & .09 & -.15 & .68 & .13 & -.03 & .13 & - & & & & & & & & & & & & & & & & & & \\
\hline \multicolumn{28}{|l|}{ Mean situation variables } \\
\hline Duty & 4.46 & 1.33 & -.02 & .01 & .04 & -.02 & .12 & .07 & .02 & - & & & & & & & & & & & & & & & & & \\
\hline Intellect & 3.78 & 1.20 & -.05 & .06 & .01 & -.06 & .14 & .09 & -.10 & .69 & - & & & & & & & & & & & & & & & & \\
\hline Adversity & 1.59 & 0.68 & -.13 & .11 & -.11 & -.12 & -.06 & .01 & -.25 & .09 & .30 & - & & & & & & & & & & & & & & & \\
\hline Mating & 2.57 & 1.44 & .03 & .07 & .16 & -.17 & .07 & .07 & .06 & -.03 & .08 & .25 & - & & & & & & & & & & & & & & \\
\hline pOsitivity & 4.54 & 0.98 & .11 & -.12 & .39 & .11 & -.08 & .15 & .46 & -.19 & -.10 & -.08 & .29 & - & & & & & & & & & & & & & \\
\hline Negativity & 3.15 & 1.23 & -.08 & .23 & -.35 & -.08 & .07 & -.05 & -.46 & .34 & .44 & .50 & .04 & -.38 & - & & & & & & & & & & & & \\
\hline Deception & 1.39 & 0.68 & -.17 & .02 & -.15 & -.12 & -.09 & -.06 & -.25 & .08 & .28 & .78 & .26 & -.11 & .48 & - & & & & & & & & & & & \\
\hline Sociality & 4.28 & 1.22 & -.08 & .11 & .24 & -.09 & .04 & .12 & .18 & .06 & .11 & .28 & .49 & .34 & .11 & .26 & - & & & & & & & & & & \\
\hline \multicolumn{28}{|l|}{ Mean affect variables } \\
\hline Positive Affect & 4.19 & 0.98 & .02 & -.08 & .42 & .12 & -.04 & .18 & .48 & -.02 & .09 & .00 & .23 & .76 & -.28 & .00 & .33 & - & & & & & & & & & \\
\hline Negative Affect & 2.36 & 0.89 & -.15 & .17 & -.32 & -.19 & -.04 & -.07 & -.48 & .17 & .23 & .49 & .13 & -.41 & .65 & .45 & .07 & -.32 & - & & & & & & & & \\
\hline Happiness & 5.66 & 1.01 & .06 & -.19 & .52 & .11 & -.05 & .13 & .65 & -.07 & -.10 & -.31 & .05 & .67 & -.63 & -.36 & .12 & .64 & -.67 & - & & & & & & & \\
\hline \multicolumn{28}{|l|}{ Mean behavior variables } \\
\hline Honesty/Humility & 6.18 & 0.78 & .26 & .03 & .08 & .09 & .14 & .02 & .13 & .10 & .04 & -.21 & -.08 & .05 & -.13 & -.23 & .02 & -.02 & -.26 & .27 & - & & & & & & \\
\hline Emotionality & 4.03 & 1.04 & -.04 & .32 & -.09 & -.12 & .11 & .03 & -.21 & .14 & .16 & .20 & .18 & -.20 & .50 & .22 & .19 & -.13 & .46 & -.44 & -.16 & - & & & & & \\
\hline Sociability & 5.23 & 0.85 & .13 & -.07 & .55 & .10 & -.03 & .20 & .47 & -.06 & .02 & -.05 & .16 & .43 & -.34 & -.08 & .33 & .46 & -.34 & .64 & .24 & -.19 & - & & & & \\
\hline Dominance & 5.16 & 0.78 & -.03 & -.21 & .44 & -.10 & -.03 & .21 & .38 & .01 & -.04 & -.08 & .07 & .40 & -.29 & -.09 & .18 & .38 & -.31 & .58 & .18 & -.29 & .47 & - & & & \\
\hline Agreeableness & 6.18 & 0.77 & .21 & .13 & .30 & .26 & .03 & .09 & .39 & -.10 & -.05 & -.25 & .03 & .45 & -.36 & -.26 & .12 & .34 & -.48 & .62 & .50 & -.24 & .58 & .37 & - & & \\
\hline Conscientiousness & 5.18 & 0.93 & .12 & -.05 & .19 & -.01 & .33 & .13 & .24 & .28 & .22 & -.02 & .00 & .07 & -.05 & -.07 & .08 & .11 & -.12 & .28 & .21 & .03 & .28 & .35 & .19 & - & \\
\hline Openness & 5.37 & 0.90 & .07 & -.17 & .32 & .03 & .12 & .27 & .25 & .15 & .20 & -.04 & -.03 & .25 & -.16 & -.05 & .10 & .33 & -.26 & .45 & .23 & -.10 & .47 & .45 & .32 & .60 & - \\
\hline
\end{tabular}


Table 8

Effects of Situation Perception at Level 1 in Study 2

\begin{tabular}{|c|c|c|c|c|c|c|c|c|c|c|c|c|c|c|c|c|}
\hline Sit.-Perc. & Duty & & Intellect & & Adversity & & Mating & & pOsitivity & & Negativity & & Deception & & Sociality & \\
\hline Behavior & $b[\mathrm{LL}, \mathrm{UL}]$ & $t$ & $b[\mathrm{LL}, \mathrm{UL}]$ & $t$ & $b[\mathrm{LL}, \mathrm{UL}]$ & $t$ & $b[\mathrm{LL}, \mathrm{UL}]$ & $t$ & $b[\mathrm{LL}, \mathrm{UL}]$ & $t$ & $b[\mathrm{LL}, \mathrm{UL}]$ & $t$ & $b[\mathrm{LL}, \mathrm{UL}]$ & $t$ & $b[\mathrm{LL}, \mathrm{UL}]$ & \\
\hline \multicolumn{17}{|c|}{ Model 1: Predicting Behavior from Situation Perception at level 1 and level 2} \\
\hline $\mathrm{H}$ & $-0.05[-0.06 ;-0.04]$ & -6.44 & $-0.01[-0.02 ; 0.01]$ & -1.00 & $-0.14[-0.17 ;-0.10]$ & -6.90 & & 1.87 & $0.12[0.10 ; 0.14]$ & $8.54-($ & & $-8.25-$ & & -7.19 & $0.00[-0.02 ; 0.01]$ & -0.33 \\
\hline $\mathrm{E}$ & $0.01[-0.01 ; 0.03]$ & 0.93 & 0.05 [0.03; 0.07$]$ & 3.85 & $0.32[0.28 ; 0.36]$ & 13.78 & $0.07[0.04 ; 0.09]$ & $4.84-($ & $0.15[-0.19 ;-0.12]$ & -7.33 & $0.36[0.33 ; 0.38]$ & 20.49 & $0.27[0.22 ; 0.32]$ & 8.32 & $0.07[0.05 ; 0.09]$ & 5.94 \\
\hline $\mathrm{X}$ & $0.02[0.00 ; 0.03]$ & 2.01 & $0.00[-0.02 ; 0.01]$ & -0.42 & $-0.03[-0.06 ; 0.00]$ & -1.56 & $0.02[0.00 ; 0.04]$ & 2.15 & $0.17[0.15 ; 0.19]$ & $12.54-$ & $-0.14[-0.16 ;-0.12]$ & -10.1 & $09[-0.12 ;-0.05]$ & -3.98 & $0.06[0.05 ; 0.07]$ & 7.38 \\
\hline A & $0.07[-0.09 ;-0.06]$ & -7.51 & -0.04 [-0.06; -0.02] & -3.60 & $-0.28[-0.31 ;-0.24]$ & -13.30 & $0.09[0.07 ; 0.11]$ & 7.07 & $0.34[0.31 ; 0.37]$ & $21.02-$ & $-0.31[-0.33 ;-0.28]$ & -22.5 & $0.28[-0.34 ;-0.23]$ & -8.41 & $0.10[0.09 ; 0.12]$ & 10.35 \\
\hline $\mathrm{C}$ & $0.25[0.23 ; 0.27]$ & 17.54 & $0.22[0.19 ; 0.25]$ & 12.66 & $-0.04[-0.08 ;-0.01]$ & -2.08 & $0.00[-0.02 ; 0.02]$ & -0.07 & $0.08[0.05 ; 0.11]$ & 4.69 & $-0.03[-0.06 ; 0.00]$ & -1.82 & $0.07[-0.10 ;-0.03]$ & -2.93 & $0.07[0.05 ; 0.09]$ & 6.05 \\
\hline $\mathrm{O}$ & $0.10[0.08 ; 0.12]$ & 8.62 & $0.17[0.15 ; 0.20]$ & 11.31 & $-0.09[-0.12 ;-0.06]$ & -5.13 & 0.04 [0.02; 0.07$]$ & 3.43 & $0.22[0.20 ; 0.25]$ & $15.43-$ & $-0.12[-0.14 ;-0.10]$ & -8.31 & $0.07[-0.11 ;-0.03]$ & -3.12 & ובע ם. & 9.56 \\
\hline $\mathrm{D}^{*}$ & $0.02[0.00 ; 0.03]$ & 2.01 & $0.00[-0.02 ; 0.01]$ & -0.42 & $-0.03[-0.06 ; 0.00]$ & -1.56 & $0.02[0.00 ; 0.04]$ & 2.15 & $0.17[0.15 ; 0.19]$ & $12.54-$ & $-0.14[-0.16 ;-0.12]$ & -10.1 & $0.09[-0.12 ;-0.05]$ & -3.98 & $061005-35$ & 3 \\
\hline \multicolumn{17}{|c|}{ Model 2: Predicting Behavior from Situation Perception at level 1 and level 2, and Happiness at level 1 and level 2} \\
\hline $\mathrm{H}$ & $3[-0.05 ;-0.02]$ & -4.62 & $0.00[-0.01 ; 0.02]$ & 0.27 & & -7.87 & $0.00[-0.02 ; 0.02]$ & -0.04 & $0.05[0.02 ; 0.07]$ & & $-0.02]$ & & & -5.89 & $-0.02]$ & -3.40 \\
\hline $\mathrm{E}$ & $0.00[-0.02 ; 0.01]$ & -0.44 & $0.03[0.01 ; 0.05]$ & 2.45 & $0.22[0.19 ; 0.26]$ & 10.52 & $0.10[0.08 ; 0.12]$ & 7.34 & & $\dagger 2.09$ & & 17.2 & $0.17[0.12 ; 0.21]$ & 5.89 & $0.12[0.10 ; 0.14]$ & 9.82 \\
\hline $\mathrm{X}$ & $0.03[0.02 ; 0.04]$ & 4.18 & $0.01[0.00 ; 0.02]$ & 1.17 & $0.06[0.03 ; 0.08]$ & 3.36 & $-0.01[-0.02 ; 0.01]$ & -0.79 & $0.04[0.02 ; 0.07]$ & $3.32-1$ & $-0.03[-0.05 ;-0.01]$ & -2.36 & $0.00[-0.04 ; 0.03]$ & -0.14 & $0.03[0.01 ; 0.04]$ & 3.12 \\
\hline A & $0.03[-0.04 ;-0.02]$ & -4.51 & $-0.01[-0.02 ; 0.00]$ & -1.12 & $0.12[-0.13 ;-0.10]$ & -10.4 & $0.03[0.02 ; 0.05]$ & 3.91 & $0.09[0.07 ; 0.12]$ & $6.66-($ & $-0.09[-0.11 ;-0.07]$ & -7.44 & $0.12[-0.16 ;-0.07]$ & -4.38 & $0.03[0.02 ; 0.04]$ & 4.12 \\
\hline $\mathrm{C}$ & $0.27[0.25 ; 0.29]$ & 19.44 & $0.24[0.21 ; 0.27]$ & 13.8 & 0.04 [0.00; 0.07$]$ & 1.87 & $-0.03[-0.05 ;-0.01]$ & $-2.20-$ & $0.09[-0.12 ;-0.07]$ & -6.41 & 0.13 [0.09; 0.16] & 6.61 & $0.01[-0.02 ; 0.05]$ & 0.66 & $0.04[0.02 ; 0.06]$ & 3.32 \\
\hline $\mathrm{O}$ & $0.13[0.11 ; 0.15]$ & 11.97 & $0.19[0.17 ; 0.22]$ & 14.44 & $0.03[0.01 ; 0.06]$ & 2.51 & $0.00[-0.01 ; 0.02]$ & 0.33 & $0.04]$ & 1.18 & $0.08[0.05 ; 0.10]$ & 5.18 & 0.05 [0.02; 0.08$]$ & 2.74 & $0.05[0.03 ; 0.06]$ & 5.08 \\
\hline$D^{*}$ & $0.03[0.02 ; 0.04]$ & 4.18 & $0.01[0.00 ; 0.02]$ & 1.17 & $0.06[0.03 ; 0.08]$ & 3.36 & $-0.01[-0.02 ; 0.01]$ & -0.79 & $0.04[0.02 ; 0.07]$ & $3.32-1$ & $-0.03[-0.05 ;-0.01]$ & -2.36 & $0.00[-0.04 ; 0.03]$ & -0.14 & $0.03[0.01 ; 0.04]$ & 3.12 \\
\hline
\end{tabular}

Model 3: Predicting Behavior from Situation Perception at level 1 and level 2, Happiness at level 1 and level 2, and PA and NA at level 1 and level 2

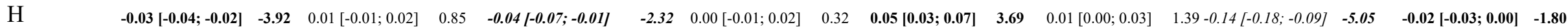

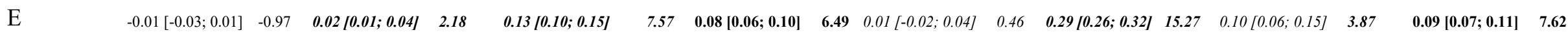
$2.01-0.01[-0.03 ; 0.001-1.76 \quad 0.03[0.01 ; 0.051 \quad 2.32-0.05[-0.07 ;-0.04)-5.30-0.02[-0.05 ; 0.01]-1.23$

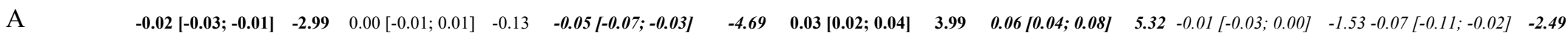

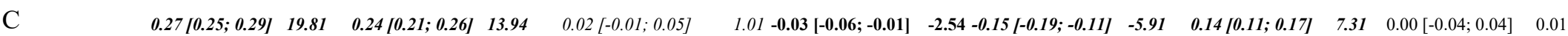

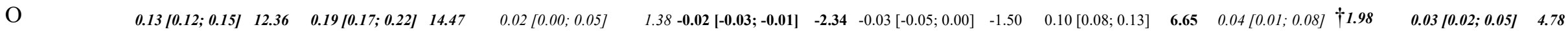
$\begin{array}{rr}0.01[-0.01 ; 0.02] & 0.81 \\ \mathbf{0 . 0 5}[\mathbf{0 . 0 4} ; \mathbf{0 . 0 6}] & \mathbf{6 . 8 7}\end{array}$ $0.03[0.01 ; 0.05] \quad 2.66$

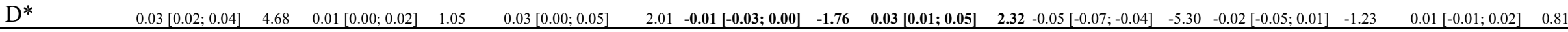

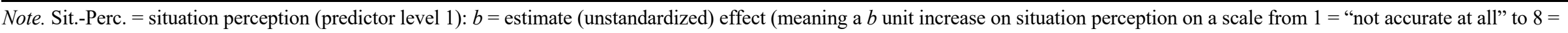
"completely accurate" corresponds to a one unit change in the criterion, bipolar rating scale, ranging from 1 to 8 ); LL $=$ lower limit of $90 \%$ confidence interval, UL = upper limit of $90 \%$

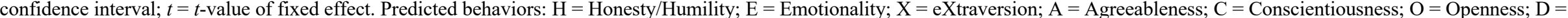
Dominance.

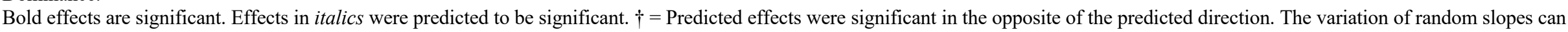
be found on the OSF, supplement E. All predictors were group-mean centered. 
Table 9

Effects of Situation Perception at Level 2 in Study 2

\begin{tabular}{|c|c|c|c|c|c|c|c|c|c|c|c|c|c|c|c|c|}
\hline Sit.-Perc. & Duty & & Intellect & & Adversity & & Mating & & pOsitivity & & Negativity & & Deception & & Sociality & \\
\hline Behavior & $b[\mathrm{LL}, \mathrm{UL}]$ & $t$ & $b[\mathrm{LL}, \mathrm{UL}]$ & $t$ & $b[\mathrm{LL}, \mathrm{UL}]$ & $t$ & $b[\mathrm{LL}, \mathrm{UL}]$ & $t$ & $b[\mathrm{LL}, \mathrm{UL}]$ & $t$ & $b[\mathrm{LL}, \mathrm{UL}]$ & $t$ & $b[\mathrm{LL}, \mathrm{UL}]$ & & $b[\mathrm{LL}, \mathrm{UL}]$ & \\
\hline \multicolumn{17}{|c|}{ Model 1: Predicting Behavior from Situation Perception at level 1 and level 2} \\
\hline $\mathrm{H}$ & $0.06[0.00 ; 0.13]$ & 1.65 & $0.05[-0.02 ; 0.12]$ & & $-0.14[-0.27 ;-0.01]$ & -1.80 & $-0.04[-0.10 ; 0.02]$ & -1.18 & $0.08[-0.01 ; 0.17]$ & & $-0.05[-0.12 ; 0.02]$ & -1.27 & $-0.18[-0.31 ;-0.05]$ & -2.21 & $0.03[-0.04 ; 0.10]$ & 0.80 \\
\hline E & & 2.19 & $0.11[0.02$ & & & 2.63 & & & & & & 7.60 & & 2.54 & & .83 \\
\hline $\mathrm{X}$ & & -0.99 & $-0.04[-0.11$ & & & & & & & & & & & & & 00 \\
\hline A & $.09 ; 0.03]$ & -0.86 & $-0.02[-0.09 ; 0.05]$ & & & & & & & & ; -0.16] & -5.9 & $-0.30[-0$. & -4.38 & & .00 \\
\hline $\mathrm{C}$ & $.09 ; 0.23]$ & 3.90 & & & & -0.24 & & & & & $-0.09[-0$. & -1.90 & $06]$ & -0.92 & & .95 \\
\hline $\mathrm{O}$ & $2 ; 0.16]$ & 2.18 & 0.14 & & $-0.07[-($ & -0.85 & & 1.61 & & 3.93 & $-0.10[-0$ & -2.23 & $-0.06[-0$ & -0.70 & & .17 \\
\hline $\mathrm{D}^{*}$ & $-0.03[-0.09 ; 0.02]$ & -0.99 & $-0.04[-0.11 ; 0.02]$ & -1.02 & $-0.06[-0.17 ; 0.05]$ & -0.88 & $-0.02[-0.07 ; 0.03]$ & -0.67 & & 3.63 & & -2.83 & & -0.62 & & 00 \\
\hline \multicolumn{17}{|c|}{ Model 2: Predicting Behavior from Situation Perception at level 1 and level 2, and Happiness at level 1 and level 2} \\
\hline $\mathrm{H}$ & $0.07[0.00 ; 0.13]$ & 1.74 & $0.05[-0.02 ; 0.13]$ & 1.25 & $-0.13[-0.26 ; 0.00]$ & -1.67 & $-0.04[-0.10 ; 0.02]$ & -1.08 & $0.06[-0.03 ; 0.16]$ & 1.08 & $-0.05[-0.1$ & -0.99 & & -2.26 & & 0.84 \\
\hline E & $3 ; 0.17]$ & 2.20 & $0.10[0.01 ; 0.18]$ & 1.89 & 0.18 [0.03; 0.33] & 1.99 & $0.11[0.0$ & 2.82 & $-0.05[-1$ & -0.72 & & 7.11 & & 2.03 & & 34 \\
\hline $\mathrm{X}$ & $09 ; 0.02]$ & -0.94 & $-0.04[-0.10 ; 0.03]$ & -1.00 & $-0.04[-0.15 ; 0.08]$ & -0.52 & $-0.02[-0.08$ & -0.72 & & 3.33 & $-0.10[-C$ & -2.43 & $-0.03[-$ & -0.37 & & 79 \\
\hline A & $0.09 ; 0.02]$ & -1.04 & $-0.01[-0.07 ; 0.05]$ & & $-0.23[-0.34 ;-0.13]$ & -3.75 & $0.01[-0.04 ; 0.06]$ & & & & $-0.16[-0$. & & $-0.28[-0$. & & & 01 \\
\hline $\mathrm{C}$ & & 4.21 & & & & & & & & & & & & 0.13 & & 21 \\
\hline $\mathrm{O}$ & & 2.49 & $0.17[0.0$ & & 0.01 & 0.13 & -0.07 & -1.76 & & 2.59 & -0.03 & -0.57 & -0.011 & -0.08 & 10] & 56 \\
\hline $\mathrm{D}^{*}$ & $-0.03[-0.09 ; 0.02]$ & -0.94 & $-0.04[-0.10 ; 0.03]$ & -1.00 & $-0.04[-0.15 ; 0.08]$ & -0.52 & $-0.02[-0.08 ; 0.03]$ & -0.72 & $0.17[0.09 ; 0.26]$ & 3.33 & $-0.10[-0.17 ;-0.03]$ & -2.43 & $-0.03[-0.14 ; 0.09]$ & -0.37 & & .79 \\
\hline \multicolumn{17}{|c|}{ Model 3: Predicting Behavior from Situation Perception on level 1 and level 2, Happiness at level 1 and level 2, and PA and NA at level 1 and level 2} \\
\hline $\mathrm{H}$ & $0.10[0.03 ; 0.16]$ & 2.55 & $0.10[0.03 ; 0.17]$ & 2.27 & $-0.03[-0.17 ; 0.12]$ & -0.31 & $-0.02[-0.08 ; 0.04]$ & -0.49 & $0.06[-0.07 ; 0.20]$ & 0.77 & $0.06[-0.04 ; 0.15]$ & 0.98 & $-0.09[-0.24 ; 0.06]$ & -1.02 & $0 ; 0.15]$ & 1.59 \\
\hline E & $0.04[-0.03 ; 0.11]$ & 0.94 & $0.02[-0.07 ; 0.10]$ & & $-0.08[-0.24 ; 0.08]$ & -0.82 & $0.09[0.02 ; 0.15]$ & 2.22 & $-0.03[-0.18 ; 0.13]$ & -0.3 & $0.26[0.16 ; 0.37]$ & 4.24 & $-0.06[-0.23 ; 0.11]$ & -0.58 & $0.13[0.04 ; 0.21]$ & .47 \\
\hline $\mathrm{X}$ & $-0.01[-0.06 ; 0.05]$ & -0.17 & $-0.03[-0.10 ; 0.03]$ & -0.78 & $0.04[-0.08 ; 0.16]$ & 0.56 & $-0.03[-0.08 ; 0.02]$ & -0.93 & & 1.73 & $-0.07[-0.15 ; 0.01]$ & -1.48 & $0.02[-0.11 ; 0.15]$ & 0.28 & $0.02[-0.05 ; 0.08]$ & 44 \\
\hline A & & 0.13 & $0.02[-0.03 ; 0.08]$ & & $-0.13[-0.24 ;-0.02]$ & -2.00 & & & & 4.00 & $-0.06[-0.13 ; 0.01]$ & -1.35 & $-0.17[-0.29 ;-0.06]$ & -2.55 & $0.06[0.1$ & 68 \\
\hline $\mathrm{C}$ & & 4.50 & & & $0.10[-0.06 ; 0.26]$ & & & & & & & 0.32 & & 0.00 & & .07 \\
\hline $\mathrm{O}$ & $0.12[0.06 ; 0.19]$ & 3.06 & $0.20[0.12 ; 0.27]$ & & $0.09[-0.07 ; 0.24]$ & 0.91 & $-0.08[-0.14 ;-0.01]$ & -1.99 & $0.05[-0.10 ; 0.20]$ & 0.52 & $0.07[-0.03 ; 0.17]$ & 1.20 & $0.06[-0.08 ; 0.21]$ & 0.70 & $0.03[-0.05 ; 0.10]$ & 0.55 \\
\hline $\mathrm{D}^{*}$ & $-0.01[-0.06 ; 0.05]$ & -0.17 & $-0.03[-0.10 ; 0.03]$ & -0.78 & $0.04[-0.08 ; 0.16]$ & 0.56 & $-0.03[-0.08 ; 0.02]$ & -0.93 & $0.13[0.01 ; 0.25]$ & 1.73 & $-0.07[-0.15 ; 0.01]$ & -1.48 & $0.02[-0.11 ; 0.15]$ & 0.28 & $0.02[-0.05 ; 0.08]$ & 0.44 \\
\hline
\end{tabular}

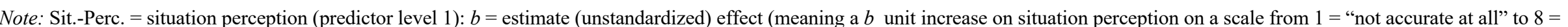

"completely accurate" corresponds to a one unit change in the criterion, bipolar rating scale, ranging from 1 to 8 ); LL $=$ lower limit of $90 \%$ confidence interval, UL = upper limit of $90 \%$

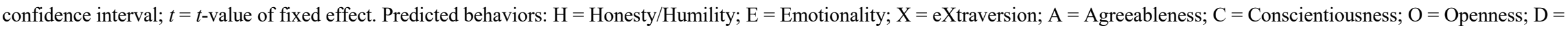

Dominance.

Bold effects are significant. Effects in italics were predicted to be significant. No effect was significant in the opposite of the predicted direction.

*The effects for Dominance were not included in the computation of Sensitivity and Specificity and the hypotheses not pre-registered. All predictors were grand-mean centered. 
Figure 1. Distribution of participants for different numbers of responses during experience sampling in Study 2

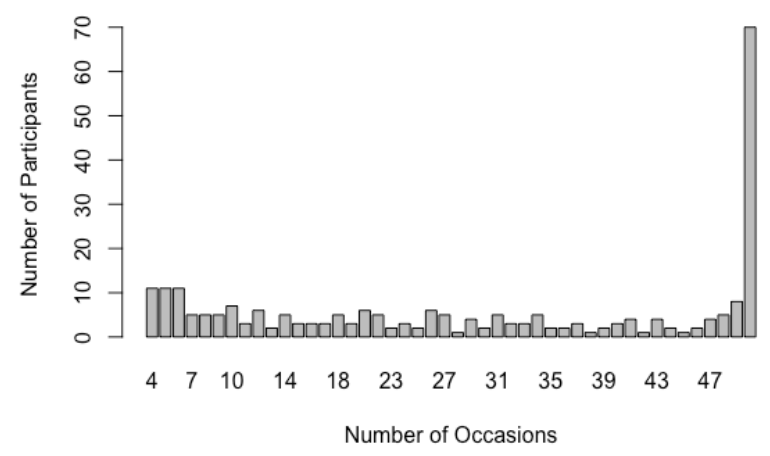

Note. The distribution of the number of experience sampling assessments across participants was as follows: $M=30.2(S D=17.43)$, Median $=31,25^{\text {th }}$ percentile $=12.25$, and $75^{\text {th }}$ percentile $=50$ measurement occasions per participant. 
Figure 2. Spaghetti plots for the prediction of extraverted behavior
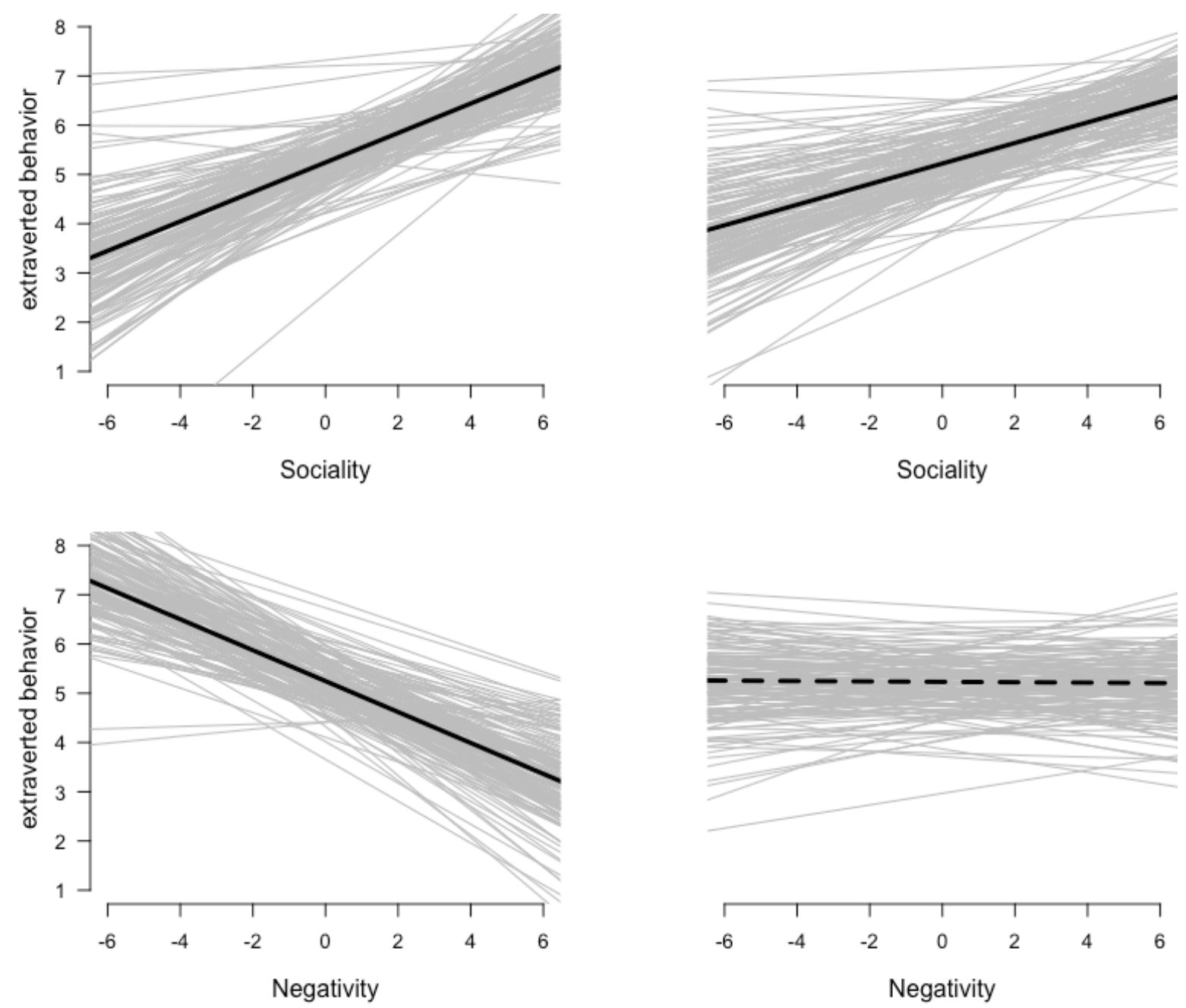

Note. Predictors are Sociality (upper panels) and Negativity (lower panels). Left panels (Model 1): prediction of behavior by situation perception at level 1 and level 2 only. Right panels (Model 3): prediction of behavior by situation perception (level 1 and 2), happiness (level 1 and 2) and positive and negative affect (level 1 and 2). Black solid indicates a statistically significant fixed effect, and the grey dotted line indicates a statistically non-significant fixed effect for situation perception on behavior. Grey lines represent individual regression lines. The predictors ( $x$-axis) were centered within person. 
Figure 3. Effects of Situation Perception on Behavior and Success of Predictions across Model 1 and Model 3
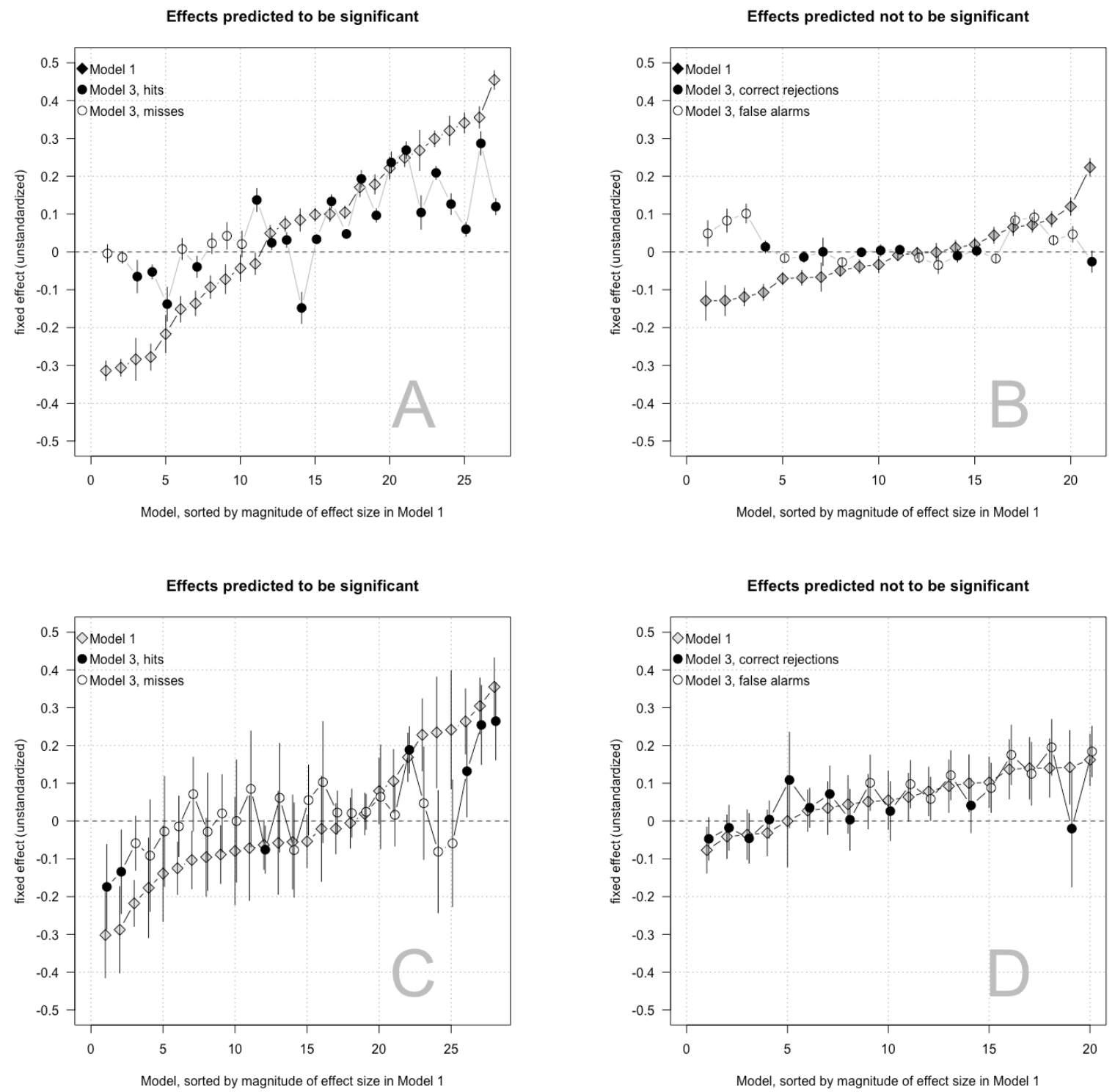

Note. Panels A and B depict effects of level 1 situation perception on behavior, panels $\mathrm{C}$ and $\mathrm{D}$ depict effects of level 2 situation perception on behavior. The left panels A and C display effects that were predicted to be significant, the right panels B and D display effects that were not predicted to be significant.

Model 1 = Effects of situation perception from Model 1; Model $3=$ Effects from situation perception from Model 3 ; hits = effects that were predicted to be significant and were significant; misses $=$ effects that were predicted not to be significant and but were significant; correct rejections = effects that were predicted not to be significant and were also not significant, false alarms = effects that were predicted not to be significant but were significant. Error bars indicate $90 \%$ confidence intervals. A black dot indicates a prediction success, am empty dot indicates a prediction error (i.e., we would have made perfect predictions if no empty dots occurred). Models are sorted by the effects size of situation perception on behavior from Model 1. 